Article

\title{
Crisis Communication after Earthquakes in Greece and Japan: Effects on Seismic Disaster Management
}

\author{
Anna Fokaefs * and Kalliopi Sapountzaki
}

Geography Department, Harokopio University of Athens, 17676 Kallithea, Greece; sapountz@hua.gr

* Correspondence: afokaeus@hua.gr; Tel.: +30-6974456303

\begin{abstract}
The communication of emergency information shortly before or after the manifestation of seismic hazards is a crucial part of disaster management. Crisis communication aims to protect, support and guide the public and emergency services throughout the response and recovery phase. In the case of seismic events, a fundamental query refers to how the information to be released to the public immediately after/before the seismic event affects disaster impacts and management. This paper addresses the uncertainty involved in emergency seismic information, identifies the sources, means, content and mode of emergency communication and points to the effects of different models of crisis communication on public perceptions, on emergency responses and, hence, on disaster management. A review of past experiences of seismic crisis communication strategies in earthquakeprone countries, namely Greece and Japan, reveals successes and failures in managing uncertainty, and in building public trust and improving response capacities. The findings include the importance of crisis communication in seismic disaster management, the levels/layers of uncertainty involved in emergency seismic information and how they impact risk perceptions, the public trust/mistrust effect on scientific and management institutions as well as some recommendations for seismic crisis communication strategies to minimize uncertainty and improve emergency responses.
\end{abstract}

Citation: Fokaefs, A.; Sapountzaki,

K. Crisis Communication after

Earthquakes in Greece and Japan:

Effects on Seismic Disaster

Management. Sustainability 2021, 13,

9257. https://doi.org/10.3390/

su13169257

Academic Editor: Ashraf Dewan

Received: 30 June 2021

Accepted: 13 August 2021

Published: 18 August 2021

Publisher's Note: MDPI stays neutral with regard to jurisdictional claims in published maps and institutional affiliations.

Copyright: (c) 2021 by the authors. Licensee MDPI, Basel, Switzerland. This article is an open access article distributed under the terms and conditions of the Creative Commons Attribution (CC BY) license (https:// creativecommons.org/licenses/by/ $4.0 /)$.

Keywords: seismic crisis; seismic emergency information and communication; uncertainty; risk perception; governance culture; Greece; Japan; seismic risk management

\section{Introduction}

The short period (of a couple of weeks) following the initial strong tremors of a seismic event is a crisis period with a state of emergency. This is confirmed by the several conceptions and definitions of a crisis: (a) events potentially leading to unstable and dangerous situations affecting individuals, groups or communities [1]; (b) events or series of events that are non-routine and unexpected, creating high levels of uncertainty and a threat or perceived threat to a community's high priority goals [2]; (c) harmful and disruptive or threatening events for organizations and communities potentially implying negative changes in security, economic, political, societal or environmental affairs, especially when they occur with little or no warning [3-6]. In general, experts and scholars view crises as "testing times" or "emergency events" wherein immediate responses are an imperative. However, immediate responses of the public and responsible organizations in crisis contexts-featured by unknown situations and destabilization of the usual frames of reference [7] - presuppose an intense flow of emergency information. Consequently, "crisis communication" in the present paper is associated with the emergency phase of the (seismic) disaster (and risk) management cycle and the need to inform and alert the public and managers about an already damaging and/or potentially harmful event. It has been suggested that the content, mode and timing of crisis/emergency communication "may either reduce and contain the harm or make the situation worse" [8].

Crisis communication in the case of earthquakes overlaps with risk communication, but the two forms of communication are not interchangeable because: (a) risk communication spans every phase of the (disaster) risk management cycle, not only the emergency; 
(b) emergency communication refers to mixed information containing facts and data on the one hand and uncertain predictions and advice on the other; (c) in emergency (and not risk) communication, decisions must be made within a narrow time constraint on the basis of imperfect or incomplete information, and these decisions may be irreversible and their outcome uncertain. This mixture of certain (about the immediate past) and uncertain information referring mainly to the predicted evolution of the extreme phenomenon, secondary hazards and damaging impacts, as well as recommended responses, has an intermediary, tentative character, meaning that it is subject to constant updating. Since this provisional information leaves room for opposing views/predictions, it can easily lead to confusion in public perceptions and actions. Only socially/politically acceptable and trustworthy information sources can counteract the chaotic situation that may emerge from a cognitive crisis on top of a post-earthquake crisis $[9,10]$. Indeed, in the case of strong catastrophic earthquakes, the general public and emergency managers seek credible scientific information (i.e., announcements of magnitude, location, damage and secondary effects, the possibility of aftershocks, advice and guidelines for responsive action) among several sources: geoscience information centers, public administration agencies, health-welfare agencies, individual experts and mass and social media.

Uncertainty is a key factor of (seismic) crisis communication [11], and while it can generate mistrust and confusion, it may also advocate information seeking [12,13]. However, eagerness and anticipation for information supply are time limited and strongly dependent on the (seismic) disaster magnitude [14].

There are several types of uncertainty involved in seismic emergency information originating from the different types of messages being aimed at emergency managers and the general public [15]:

- Informative messages, reporting earthquake parameters (magnitude and epicenter); these are released near real time after the earthquake. Messages regarding injuries or damages to infrastructure (e.g., building collapses) several minutes up to hours after an earthquake are also informative. This information is continuously updated.

- Warning messages about other secondary effects and their characteristics (e.g., tsunamis, landslides etc.). This information follows (and is based on) the initially resealed messages about earthquake parameters. Forecasting of aftershocks also belongs to this category. When (and where) earthquake early warning practices are established (e.g., Japan and the USA), alerts are issued in order to warn the public and systems a few seconds before the destructive shaking.

- Consulting messages about the appropriate safety measures and actions to be undertaken (e.g., going to open areas or moving to higher places and for how long). This information is available shortly after an earthquake and is also continuously updated.

- Guiding messages regarding instructions on assistance retrieval, refuge spaces, evacuation routes, health facilities, emergency telephone numbers etc. This information is available usually a few hours after an earthquake and it is updated continuously.

The information released within the first minutes following the event carries background uncertainty due to limited knowledge and incomplete data, which are constantly updated/revised as the event evolves, thus adjusting/(re)forming the content of the consulting and guiding information (e.g., evacuation). Indeed, the initial information reporting earthquake parameters is based on preliminary estimations and measurements, and is often non-precise or incomplete. On the other hand, the initial warnings (e.g., possibility of tsunami generation or aftershock occurrence) are based on computed database scenarios or on simplified methodologies and seismicity catalogue elaboration rather than direct observations. In particular, in the case of earthquake predictions, these are mainly based on precursory phenomena (e.g., ground deformation, geo-electric anomalies and abnormal seismic activity). Uncertainty however, is not only epistemic, it may also come from the different perceptions or multiple knowledge frames of people and managers (as affected by preparedness levels besides), thus leading to different attitudes or interpretations of consulting and instructive messages. Apart from the uncertainty related to the phenomenon, 
scientific knowledge and risk perceptions, coordination and governance issues (related to the implementation of instructive messages) and technology limitations and failures add layers of uncertainty.

In summary, uncertainty in seismic emergency periods originates from both the probabilistic information released by scientific institutions and the situation of the crisis itself, leaving the public puzzled with questions: What are the causes of the crisis and how long will it take to return to normality? Who is responsible for crisis management, and where do the protection measures come from? While people often want clear and quick answers in order to make sense of the situation and make decisions on actions to take to protect themselves, it is often difficult for emergency managers to meet these information needs. The crisis might still be unfolding, the full scale of the disaster may still be unknown and the collection and elaboration of empirical data may take a long time to become useful information to be communicated with the public.

\section{Research Queries, Scientific Background and Methodology}

\subsection{Scope and Research Queries}

While there is a sizable body of research on best practices in risk and crisis communication, and despite acknowledgement of the crucial role of uncertainty, there is a theoretical gap on good practices and principles for communicators to manage crisis information uncertainty [16]. The authors, aspiring to generalizable principles for seismic crisis communication, attempt to conduct comparative empirical research on two country cases of the developed world featured by distinct risk cultures (Greece and Japan). The ultimate objective is the handling of uncertainty to the best outcome of disaster management. Relevant research queries are as follows: (a) What layers/levels of uncertainty are involved in seismic emergency information released to the public? (b) How do these uncertainty layers relate to the source, content, channels and modes of seismic crisis communication? (c) What is the impact on public perceptions and responsive actions? (d) How are crisis emotions and management failures related to uncertainty? (e) What are "acceptable" levels of uncertainty, and how does uncertainty management predict seismic emergency and disaster-related outcomes? The following paragraphs map current and incomplete theoretical knowledge regarding interrelations between seismic crises, seismic emergency information and communication, uncertainty, risk perception and risk cultures as well as emergency responses.

There are two basic challenges in managing seismic emergency information uncertainty: First, to deal with epistemic uncertainty and secondly, to deal with uncertainty involved in emergency communication (owing to diverse risk perceptions and knowledge frames, governance obstacles and technological limitations). The present work focuses principally on the second challenge.

\subsection{Dealing with Uncertainty in Scientific Seismic Infomration}

Every form of prognostic and probabilistic information about a seismic event that has or has not already started includes many levels of uncertainty. According to [17], these "range from the natural stochastic uncertainty ("aleatory" - the variability of the system) to the epistemic uncertainty (meaning lack of knowledge), also from scientists being uncertain about their knowledge and data, through to disagreement amongst scientists ... " In hazard assessments, aleatory uncertainty is treated probabilistically and epistemic uncertainty is treated by various mathematical models (Figure 1). In Seismic Hazard Assessment, aleatory uncertainty is typically represented by probability distributions and epistemic uncertainty is represented by weighted alternative assumptions in logic-tree approaches. Some key approaches in handling uncertainty will be mentioned but providing a detailed survey of the related literature is beyond the goals of the present paper. 


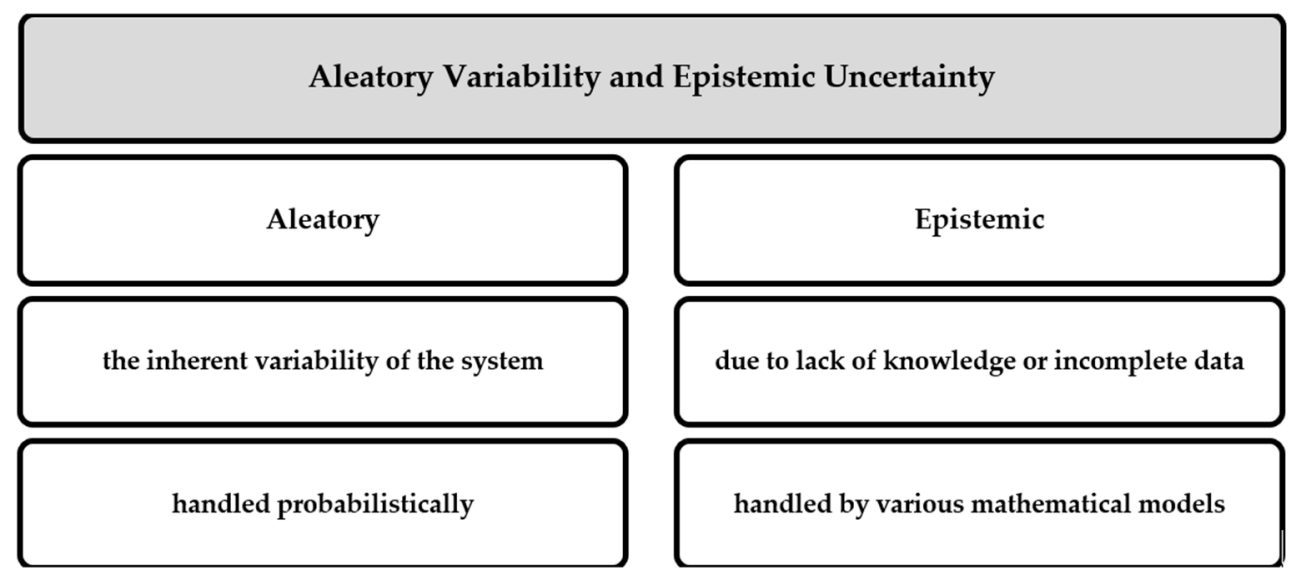

Figure 1. Scientific uncertainty classification and quantification practices. Source: authors' elaboration.

Regarding the parameters of initial earthquake announcements, especially the quality of magnitude determinations, it is expressed by statistical techniques mainly by standard error estimations. The next concern is about the possible aftershocks. Aftershock forecasting and the uncertainty involved are handled by various statistical approaches, e.g., the epidemic-type aftershock sequence (ETAS) model $[18,19]$ and the stress release model developed by [20]. A characteristic example is the operational aftershock forecasting in New Zealand [21] following the Canterbury Earthquake Sequence: The expected number of different magnitude earthquakes and/or ground shaking for specified time periods have been released to the public and key stakeholders as tables, charts and maps and the relative uncertainties were expressed by probability distributions.

Probabilistic Seismic Hazard Assessment (PSHA) is considered to be in the first line of defense in mitigating seismic risk [Field and Milner 2018]. It is well documented in the literature that PSH maps carry both types of uncertainty [22-24]: (1) aleatoric uncertainty associated with seismic wave propagation, treated by the standard deviation of the attenuation relation and (2) epistemic uncertainty related to the characteristics of seismic zones, earthquake recurrence rate and maximum earthquake magnitude. PSHA outputs are communicated to decision makers and the public in forms of seismic hazard contour maps or hazard curves where the uncertainty is illustrated as the probability that a given site will experience ground motion intensity exceeding a certain value within a target period. A characteristic example is Japan (see Section 3.2.1) Application of this method for PSHA in N.E. Italy is analyzed in [25].

Accordingly, in the Probabilistic Tsunami Hazard Assessment (PTHA), the probability of exceeding specific levels of tsunami intensity metrics (e.g., run-up or maximum inundation heights) in time and space is illustrated in hazard maps or hazard curves. Epistemic uncertainty relates to earthquake rupture processes, while inundation or run-up processes involving the resolution and accuracy of bathymetry and digital elevation models have a significant impact [22]. In the case of a real earthquake event (Tsunami Early Waning, TEW), the alert level and tsunami impact estimation are based on pre-simulated scenarios. The dominant uncertainty in TEW as well as in long-term PTHA originates from the preliminary seismic information [26]. One way to handle this source of uncertainty is by adopting the maximum possible earthquake magnitude generating the maximum probable tsunami wave [27]. Another way is to use the PSHA outputs to tsunami simulations [28].

Finally, SHA is usually combined with the vulnerability characteristics of buildings in order to obtain the degree of probable structural damage [29]. The developed approach for vulnerability assessment in Europe is based on the vulnerability index method: different vulnerability classes are assigned to different building typologies. Rapid Visual Screening Assessment methods is another popular empirical approach for rapid vulnerability assessment. On the other hand, analytical methods (Non-Linear Time History Analysis and Non-Linear Static or Pushover Analysis) can handle all kinds of uncertainty in de- 
termining the level of damage to structural elements. Modeling the behavior of critical structures due to earthquake load contributes significantly to the post-earthquake damage assessment [30,31].

\subsection{Uncertainty Communication in Seismic Crisis Periods}

As made evident in the Introduction and acknowledged in the literature, "crises are by definition high-uncertainty events, where information is often not immediately available" [11]. This is also true for seismic crises, because the information released immediately after the first strong tremors (should it reach the exposed population) always falls short of the public's information requirements. For instance, first announcements through the mass media usually refer to the magnitude and epicenter of the initial event but not to other types of information most critical for the population affected or to be affected: anticipated frequency, time and magnitude of after-shocks, geographical extent of the hit area and locations of probable building collapses, number and location of people injured, safe and unsafe buildings to stay inside or evacuate, damages and the period of time needed for recovery and re-operation of the disrupted electricity and mobile communication systems etc. These information gaps will most likely be covered much later, leaving the affected population under a condition of uncertainty for a long period of time.

The problem involves information gaps creating uncertainty in a crisis period, especially when threatening conditions are evolving, and the authors of [32] suggest that "the immediate communication needs during a crisis are to reduce uncertainty allowing audiences to create an understanding of what happened so that they may respond appropriately" (see also [16]).

The description of the condition of uncertainty in [33] seems broad and encompassing of all versions of (seismic) emergency information deficit: "uncertainty exists when details of situations are ambiguous, complex, unpredictable, or probabilistic; when information in demand is unavailable or inconsistent; and when people feel insecure about their own state of affairs and state of knowledge in general".

According to [16], to date, there is no known crisis communication theory that explicitly addresses uncertainty. Several crisis communication theories relate to uncertainty but do not clarify how communicators should integrate uncertainty into their work. The only theories of communication uncertainty exist outside of crisis research. The most well-known are the uncertainty reduction theory, the uncertainty management and the problematic integration theory. The first, originating from the work of [34], considers uncertainty as the number of possible outcomes of a situation, and it is based on the assumption that humans are motivated to decrease uncertainty about themselves and others. From this perspective, uncertainty is an adversity, something that should always be mitigated. It has been criticized in that it does not consider the modeling of unusual, multifaceted communication situations that are commonplace in crisis periods. Researchers have responded to this criticism by adding moderating variables, such as culture.

The adherents of the second theory [35], i.e., uncertainty management theory, argue that people experience uncertainty in different ways and not only as a negative situation that should be reduced. Depending on the cultural context and other factors, uncertainty may be positive, neutral or negative. In particular, [16] quotes the argument of [36] that people may opt to seek information to increase uncertainty and of [37] that people may avoid information altogether to maintain hope and optimism. The third, i.e., problematic integration theory, adopts the view that information seeking can resolve uncertainty but adds that information may be unavailable [38]. The theory refers, in particular, to difficult conditions of mismatch between information demand and supply, which are well-fitted to the seismic crisis context: affected people may not know when information will be available, whether the desired information will be available by when they need it and whether knowing the information will matter to them personally. 
Uncertainty interrelates with trust, while public trust depends on the sources and means of communication of emergency information. The authors of [39] cited in [16] argue that "the more the public put trust on government or the communicating institutions, the better they are able to handle fear and panic in crisis contexts ... For this reason it is better for the official communicators to admit uncertainty than to present information as certain and be proven wrong later". Emergency communication cannot be successful without the public's trust in message sources; previous errors, such as releasing false information, may decrease public trust in information-releasing institutions.

Matters of complexity, uncertainty and trust arise not only among the public receiving information from scientific institutions and official communicators but also among official institutions and emergency managers when facing huge quantities of data and information originating from social media platforms. In the chapter titled "Decision-making under uncertainty", the authors of [40] argue that technological progress has enormously increased the lay public's connectivity and continues to promise broader bandwidth and unknown computational power to all (see also [41]). These authors argue that the use of social media that first gained acceptance in the Haiti earthquake has become "mainstream" since then. Moreover, technology-driven data sources, such as GPSs, radiofrequency-based identification tracking, remote sensing, satellite imagery and drones, enable real-time monitoring [42]. The various data extracted from sources ranging from sensors to social media are fraught with different types of uncertainty. Therefore, not only have scientists lost the exclusivity to create and disseminate seismic crisis information, but they have to prove that their approach, data collection and advice match the purpose and context of the specific crisis in question.

Finally, seismic crisis communicators should consider power dynamics in their approach to uncertainty. The authors of [40] suggest that seismic or other crisis information holders can strive to maintain asymmetrical levels of information access and uncertainty to gain power over others. As an example, preventing relief actors from collecting information on humanitarian needs has proved to be a means for authoritarian political regimes to retain power during and after crisis periods.

Consequently, the content and sources of emergency information and means of communication and information exchange between scientific institutions, governmental and non-governmental managers and the public affect the levels of uncertainty and trust in the crisis context.

The authors conducted empirical research on seismic crisis communication strategies, norms and practices to identify their impact on the dynamics of the crisis in two earthquakeprone countries, namely Greece and Japan. This is a comparative analysis of (a) the sources of emergency information and the process of transmission, (b) the types of uncertainty involved and (c) the content of messages including uncertainty handling ... The comparative analysis was carried out during two distinct chronological periods: the normal period and the emergency period. The first was accommodated by an analysis/review of the administration structures responsible for seismic crisis communication and management in the two countries and the legislations governing the flow of emergency information (Section 3). Additionally, semi-structured interviews with key informers and online questionnaires to key audiences in Greece were used to address seismic risk perceptions, information needs and trust of the respondents in the authorities. The second, i.e., the analysis in the emergency period (Section 4) was a test on how the crisis communication strategies/patterns of the two countries work in practice. Section 4 is composed of case studies of actual seismic crisis events to elevate communication successes and failures. Section 5 offers a discussion on the causal relationships between the basic factors connecting seismic crisis communication with emergency management: handled or unhandled uncertainty, risk perceptions, administration structures and cultures, trust deficits and probable secondary crises (cognitive or other). Section 6 is devoted to conclusions and recommendations. The analytical methods employed (apart from the reference to the statistical methods used for the determination of scientific seismic uncertainty) are a combination of qualitative 
and quantitative approaches pertinent to political science and communication research: Content Analysis of seismic information messages, (Institutional) Process Tracing of seismic information transmission, semi-structured Interviews, Questionnaire Surveys and test Case Studies of crisis experiences (in Greece and Japan).

\section{Sources, Types and Modes of Emergency Communication of Earthquake Information: Greece and Japan}

\subsection{Greece}

3.1.1. Public Administration Agencies as Emergency Information Sources and Crisis Management Authorities

The basic public body at the national level responsible for emergency management in Greece in cases of strong and damaging seismic events is the General Secretariat of Civil Protection (GSCP), a subdivision of the Ministry of Citizen Protection. All responsibilities of the public bodies at central, regional and local levels are described in detail in national level official plans (Xenokratis General Plan and Egelados Plan. For more details, visit https: / /www.civilprotection.gr/, accessed on 1 February 2021). In the event of a damaging earthquake, GSCP announces earthquake reports regarding the event's parameters (retrieved by the Geoscience Information Centers-see Section 3.1.2) with guidelines for self-protection. Instructions on where to address help requests are also publicized. This information is released to the public through GSCP's official website, official social media accounts and breaking news on TV. Rescue and rehabilitation operations, humanitarian support and informing the public about relevant issues are coordinated and monitored by GSCP in close collaboration with the local authorities. In emergency periods, the local and regional coordination centers have the upper hand regarding emergency management decisions and accordingly communicate appropriate actions, such as evacuation orders and declaration of emergency. During the critical minutes shortly after the seismic disaster, the size of the impact is (almost) unknown (high epistemic uncertainty). It is only after the rescue services, police and fire service as well as media representatives reach the affected areas that the needs for coordination and operational actions become clear. However, the arising challenge is addressing the ambiguity due to multiple ways of interpreting the mostly unspecific instructions. An additional layer of uncertainty may come from the interruption of telecommunication services (telephone and mobile network).

At the same time, the policy for seismic protection in Greece is drafted and coordinated by the Earthquake Planning and Protection Organization (EPPO), supervised by the Ministry of Infrastructure, Transport and Networks. EPPO's main objectives and actions are: to provide and disseminate information for the prevention, preparedness and management of seismic risk/disaster; to increase awareness and seismic risk education of the population; and to strengthen the seismic capacity of building structures. In the case of a strong earthquake, EPPO provides an initial evaluation of the earthquake's impact and building damages after communication with the local police departments (by telephone) and by organizing on-site visits to the areas. Similar to GSCP, the lack of knowledge characterizing the first minutes after the seismic event and technical problems such as network service failures enhance uncertainty.

EPPO is supported by the Permanent Special Scientific Committee for the Assessment of Seismic Hazard and the Evaluation of Seismic Risk (PSSC). PSSC is responsible for the assessment of the seismicity during the seismic crisis-including persistent seismic activity recorded in a particular area, e.g., swarms-and the possibility of aftershock occurrence, as well as evaluation of the submitted short-term and long-term earthquake predictions by organizing ad-hoc meetings with panels of scientists, policymakers and local first responders. The panel is composed of science advisers, decision makers and emergency managers, reflecting different knowledge backgrounds, needs and perspectives. Consequently, seismic information carries partial knowledge, ambiguity due to conflicts and inherent variability. The conclusions and recommendations of PSSC meetings after a seismic crisis are released to the public through the official webpages of EPPO and 
GSCP, traditional media (TV and radio), social media and news websites. To date, not one earthquake prediction has been communicated by PSSC members to the public in Greece.

The Institute of Engineering Seismology and Earthquake Engineering (ITSAK) is a research unit of EPPO operating a strong motion network (accelerometers) installed in major Greek cities. ITSAK releases automatic ShakeMaps, which are widely used to illustrate the ground motion and shaking intensity following significant earthquakes. The uncertainty of these automatic ShakeMaps is related to the preliminary earthquake parameters (epistemic uncertainty). As soon as real-time strong motion data are delivered and revised and macro-seismic observations of the effects are available, the ShakeMaps are updated. GSCP and EPPO perform close collaboration during earthquake crisis in terms of participating in PSSC emergency meetings and realizing common/parallel on-site visits for evaluation of the earthquake impact.

At the regional and local (municipal) level, the Directorate of Civil Protection and the Municipal Office for Civil Protection exercise prevention, preparedness, risk communication and recovery competences. The municipalities affected by the seismic crisis, after communication with the local responders, gather information on earthquake damages or other induced phenomena and inform the Regional Administration in order to coordinate and prioritize the civil protection actions at the local level. The uncertainty involved in the emergency information released is reduced as long as more knowledge is obtained, especially by means of on-site visual inspections. Municipalities are also responsible for traffic arrangements, evacuation orders, citizen requests for temporary residence and damage compensation. Although the responsibilities are well described in official plans, the experience confirms important delays in the supply of critical information for local emergency managers and the affected population as well as misinterpretations regarding responsibilities. The recent Mw5.2 Athens in 19 July 2019 revealed important confusion on issues such as which public body (EPPO or the municipalities) is responsible for receiving requests for the emergency assessment of building safety (semi-structured interview with EPPO officer).

The structure described above evidences fragmentation of responsibilities for the dissemination of emergency information and guidance in both the horizontal and vertical senses. This condition puts in question coherence and consistency of information and guidance.

\subsubsection{Geoscience Information Centers}

Long-term monitoring of seismic activity in Greece is being realized by the Hellenic United Seismic Network (HUSN) (For more details and map station, visit http: / / www.gein.noa.gr / en/networks / husn, accessed on 1 February 2021), unifying the seismological networks of four Greek institutes and universities. The Institute of Geodynamics of the National Observatory of Athens (NOAGI) is the leading earthquake analysis and monitoring center in Greece, monitoring the HUSN, the strong motion network, the global positioning system (GPS) stations network, the tsunameters network and the seismological portable network, continuously operating at all times with complete shift staff. Under NOAGI's coordination, the information regarding the on-going seismic activity is disseminated in the form of common announcements for events with a local magnitude over 4.0 (on the Richter/local magnitude scale). NOAGI's automatic system determines the rapid earthquake parameters (location, magnitude and depth) within about three-four minutes from the earthquake's origin time. This information is automatically published in NOAGI's website to inform the authorities and the public. The rapid earthquake parameters are also sent to the GSCP's Operations Center by automatically generated email and SMS messages.

Measurements of the earthquake size are subject to inherent epistemic uncertainty and gathering of more data allows more accurate measurements that are delivered from trained seismologists within 8-15 min. NOAGI's webpage is then updated, and management authorities (predominantly GSCP and EPPO) are informed by email, SMS and fax with the revised data. The public can obtain earthquake information by calling the NOAGI 
operations center and listening to a recorded audio message, by talking directly to a duty officer or even by visiting the website updated with the latest earthquake alert. Uncertainty regarding the exact scale of a strong earthquake drops to the minimum when the moment magnitude $(\mathrm{Mw})$ is determined. However, this achieved in no less than $15 \mathrm{~min}$ after the earthquake's occurrence and requires manual processing. The solutions are published in NOAGI's website and also supplied to the European Mediterranean Seismological Centre (EMSC).

The development of technology has offered immediate access to seismic information. The public has access to the rapid/initial earthquake information through cell phone applications (e.g., LastQuake of EMSC (LastQuake official webpage https://m.emsc.eu/, accessed on 5 April 2021). Such internet applications notify people in near real time when an earthquake hits a region of interest. Announcements also contain data related to the possibility of aftershocks (expected numbers of aftershock events, magnitude range and duration of the aftershock activity). This kind of information reflects high uncertainty due to its probabilistic content. There is no official operational framework of forecasting (e.g., a statistical model of aftershock rates) established in Greece, let alone the communication of forecasts to the public.

Finally, NOAGI provides automatic ShakeMaps of the estimated distribution of macroseismic intensities. At a later stage, these maps are enriched by EPPO-ITSAK with real time data. These maps are available in the official webpage of the Hellenic Strong Motion Network webpage (For details visit https: / / accelnet.gein.noa.gr/, accessed on 1 February 2021). These maps are characterized by aleatory variability and epistemic uncertainty.

The Hellenic National Tsunami Warning Center (HL-NTWC), supported by the tide gauge network, is the NOAGI's unit that is responsible for issuance of tsunami warning messages (TWMs) for Greece and the eastern Mediterranean Sea (For details visit http: //hl-ntwc.gein.noa.gr/en/services.html\#close, accessed on 15 April 2021). The threat level of the warning messages (released within about three minutes from the earthquake origin time, Figures 2 and 3) is based on rapid initial earthquake assessment (location, magnitude and depth), and the messages are usually issued and disseminated after earthquakes of $M \geq 5.5$ with epicenters offshore or close to coastal zones. Underestimation of the earthquake magnitude or epicenter inaccuracies may lead to a false alert level. TWMs are classified into three levels (information, advisory and watch) based on increasing wave severity (wave height and run-up) as well as possible effects on coasts. The TWMs are sent (by e-mail, fax and the Global Telecommunication System (GTS) simultaneously to the operation center of GSCP, the Intergovernmental Oceanographic Commission of UNESCO (IOC-UNESCO), the Emergency Response Coordination Centre of the European Union (ERCC), the Joint Research Centre (JRC) and 17 agencies of 12 states subscribers (Analytical information can be found in HL-NTWC's official webpage http:/ /hl-ntwc.gein.noa.gr/en/, accessed on 15 April 2021). An ongoing message is sent in the case of an observation of sea level change in the tide gauge records, providing information about the wave heights at a specific time and location, while the initial alert message is canceled when no sea level change is detected. 


\begin{tabular}{|c|c|c|c|c|c|c|}
\hline \multirow[b]{2}{*}{ Focal Depth } & \multirow[b]{2}{*}{ Epicentre Location } & \multirow[b]{2}{*}{ Mw } & \multirow[b]{2}{*}{ Tsunami Generation Potential } & \multicolumn{3}{|c|}{ Tsunami Message Type } \\
\hline & & & & Local & Regional & Basin-wide \\
\hline \multirow[b]{6}{*}{$<100 \mathrm{Km}$} & \multirow[b]{2}{*}{$\begin{array}{l}\text { Offshore or close to the } \\
\text { coast }(\leq 40 \mathrm{Km} \text { inland })\end{array}$} & $5.5 \leq M \leq 6.0$ & nil & information & information & information \\
\hline & & $6.0<M \leq 6.5$ & $\begin{array}{l}\text { Weak potential for a destructive } \\
\text { local tsunami }(<100 \mathrm{~km})\end{array}$ & Advisory & information & information \\
\hline & $\begin{array}{l}\text { Inland }(>40 \mathrm{Km} \text { and } \\
\leq 100 \mathrm{Km})\end{array}$ & $5.5 \leq M \leq 6.5$ & nil & information & information & information \\
\hline & \multirow{3}{*}{$\begin{array}{l}\text { Offshore or close to the } \\
\text { coast }(\leq 100 \mathrm{Km} \text { inland) }\end{array}$} & $6.5<M \leq 7.0$ & $\begin{array}{l}\text { Potential for a destructive local } \\
\text { tsunami }(<100 \mathrm{Km})\end{array}$ & Watch & Advisory & information \\
\hline & & $7.0<M \leq 7.5$ & $\begin{array}{l}\text { Potential for a destructive regional } \\
\text { tsunami }(\leq 400 \mathrm{Km})\end{array}$ & Watch & Watch & Advisory \\
\hline & & $M>7.5$ & $\begin{array}{l}\text { Potential for a destructive basin- } \\
\text { wide tsunami }(>400 \mathrm{Km})\end{array}$ & Watch & Watch & Watch \\
\hline$\geq 100 \mathrm{Km}$ & $\begin{array}{l}\text { Offshore or inland } \\
\leq 100 \mathrm{Km}\end{array}$ & $M \geq 5.5$ & nil & information & information & information \\
\hline
\end{tabular}

Figure 2. Decision matrix regarding the type of tsunami message that should be formulated and disseminated for the Mediterranean basin as revised in March 2021. Source: HL-NTWC official website.

\begin{tabular}{|l|l|l|}
\hline \multicolumn{1}{|c|}{ Message type } & \multicolumn{1}{|c|}{ Tsunami Wave } & \multicolumn{1}{c|}{ Effects on the coast } \\
\hline Tsunami Watch & $\begin{array}{l}\text { Tsunami wave height greater than } 0.5 \mathrm{~m} \text { and/or } \\
\text { tsunami run-up greater than } 1 \mathrm{~m}\end{array}$ & $\begin{array}{l}\text { Coastal inundation, potentially including all the phenomena described as } \\
\text { potential coastal effects corresponding to tsunami advisory }\end{array}$ \\
\hline Tsunami Advisory & $\begin{array}{l}\text { Tsunami wave height less than } 0.5 \mathrm{~m} \text { but larger than } \\
0.2 \mathrm{~m} \text { and/ or tsunami run-up less than } 1 \mathrm{~m}\end{array}$ & \begin{tabular}{l} 
Currents, bore, recession, damage in harbours, small inundation on beaches \\
\hline Information
\end{tabular} \\
\hline
\end{tabular}

Figure 3. Tsunami message type and respective tsunami wave severity obtained from the official webpage of the HL-NTWC.

Only recently (beginning in 2020) has GSCP disseminated TWMs to the public (see Section 4). Forecasting the characteristics of tsunami waves involves significant epistemic uncertainty related to not only earthquake rupture processes but also inundation or run-up processes that are strongly dependent on topographical effects, flow dynamics and land surface friction [22]. A significant component of ambiguity is also present in the response behavior of the population at risk (e.g., ignorance or underestimation of the risk by the local community; see Section 4.1).

Unquestionably, the existence of only one leading official agency reporting earthquake and tsunami scientific information is a merit of the emergency communication system in Greece, all the more so as it benefits from consensus and acceptance by most relevant university laboratories in the country. The initial-stage of TWMs is bedeviled by the possibility of failures of technology in the acquisition and elaboration of necessary data, i.e., an additional layer of uncertainty. During the subsequent stage of information supply on emergency operations and safety guidance, the information is bedeviled by higher uncertainty, inconsistency and delays.

\subsubsection{Independent Announcements by Scientists}

As mentioned in Section 2.3, uncertainty is interconnected with power and ethics; for instance, ethical issues arise regarding geoscientists' social and individual behavior [43].

Very often, before, during and after earthquakes, independent scientists and experts make statements via mass media (TV, radio etc.) and social media (e.g., posts on Facebook accounts), or their statements are uploaded on open-access scientific webpages. These statements may involve rapid information following an important earthquake event or guidelines regarding safety and assistance but also non-official earthquake predictions, aftershock forecasts, criticism towards or comments on official evaluations or response capacity. This often becomes a difficult problem to handle, especially when non-official statements regarding earthquake prediction are communicated to the public in a manner that breaches official regulations. The public usually trusts the recommendations of researchers and scientists more so than those of governments. This situation may evolve into a double crisis, i.e., a crisis of scientific controversy on top of a real seismic crisis [44], and result in an increase in public confusion, distrust, insecurity, distraction and panic.

\subsubsection{The Role of Media and Social Networks}

The most common source for the public to obtain information about an earthquake in Greece is the breaking news on TV and radio programs. Journalists relay the rapid 
seismic information of the first minutes as determined by the geoscience institutions and organize on-site visits to the affected areas in order to collect and disseminate additional information about damages and victims. TV and radio also facilitate dissemination of instructions and advice issued by the management authorities. However, more often than not, seismologists' opinions contradict each other in the public and lead to uncertainty and perceptional confusion. An instructive example is the case of intense seismic activity in northwest Peloponnese (offshore of the town Amaliada) in February 2019. Five earthquake events with magnitudes of 4.2-4.7 were strongly felt, and, at the same time, a prediction of an upcoming event larger than 6.0 in western Greece was circulated through the media (Facebook). EPPO then was accused of a two-week delay in organizing a meeting to evaluate the prediction. Panic occurred among the local people, who slept outside their houses for days and weeks [45]. Power relations and antagonisms within and among the scientific community, media and politicians play a crucial role in public risk perceptions, in growing uncertainty and the generation of secondary, cognitive crises.

Nevertheless, social media, not only in Greece but worldwide, may contribute to first responders' and aid organizations' evaluations of the situation, issue warnings, provide instructions, identify survivors and victims and encourage volunteers and donations.

An online questionnaire survey conducted by the authors and addressed to university students and researchers-academics in Greece in March 2020 indicated that 70\% of the participants prefer to use the internet (news websites) and social media in order to obtain information after the occurrence of earthquakes. In the same survey, GSCP was identified as the most trusted agency in terms of the provision of information regarding security during earthquake crises $(66 \%)$.

The flowchart below (Figure 4) summarizes emergency information flow and the layers of uncertainty involved in each stage of communication.

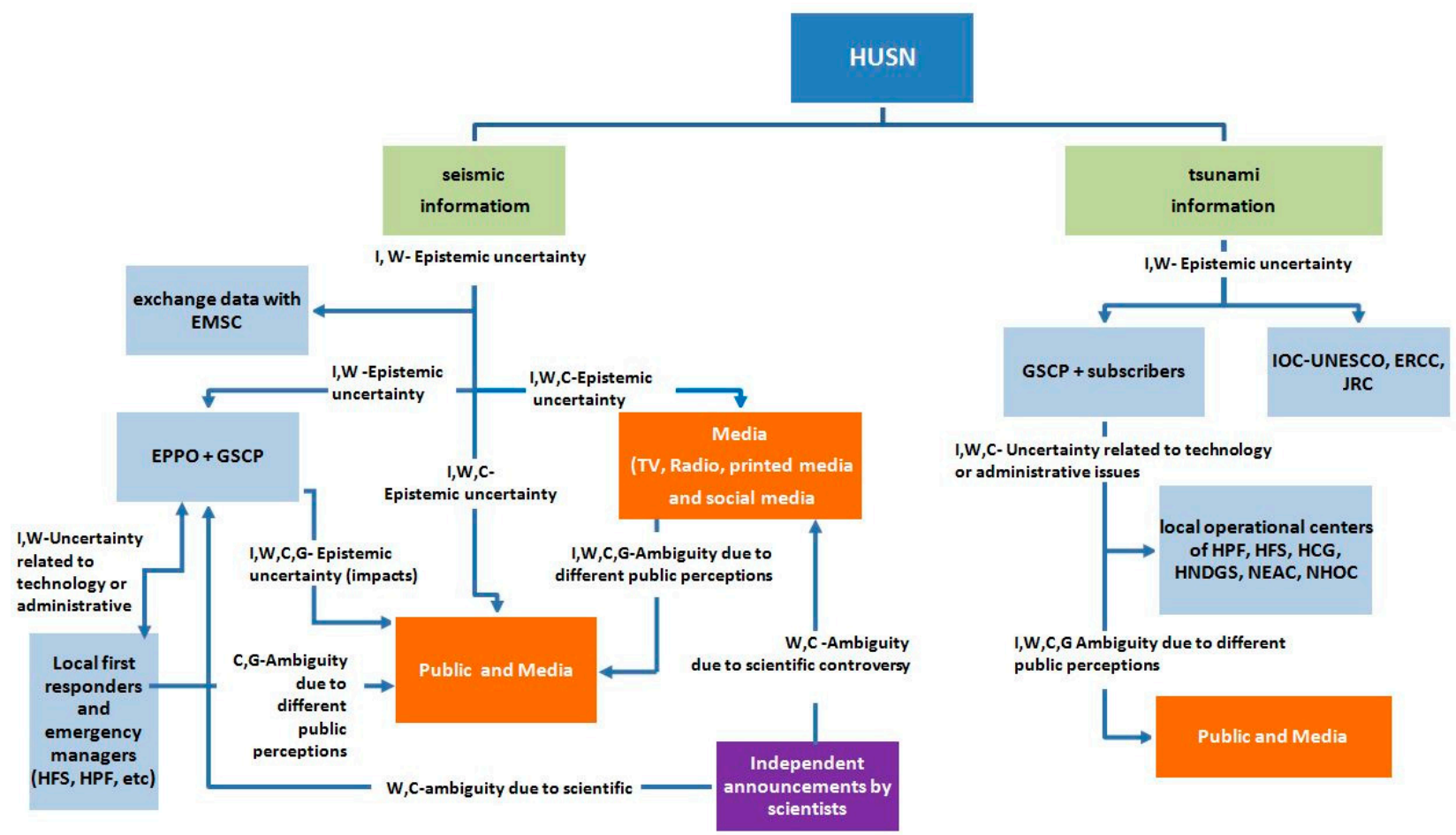

Figure 4. Flow chart of emergency seismic and tsunami information in Greece and the types of uncertainty involved in each phase of seismic crisis communication. Types of messages (see Section 1): I = Informative, W = Warning, C = Consulting, $\mathrm{G}=$ Guiding. Abbreviations of Organizations are explained in Abbreviations. Source: authors' elaboration. 


\subsection{Japan}

\subsubsection{Geoscience Information Centers}

Japan is one of the most seismically active regions in the world and is also located in a convergent plate boundary. The country has a rich experience in strong, devastating earthquakes, which are quite often associated with tsunami generation. After the 1995 earthquake disaster in Kobe, which killed 6434 people and destroyed over 100,000 buildings, the Special Measure Law on Earthquake Disaster Prevention was enacted to develop a robust policy on earthquake disaster prevention. The Headquarters for Earthquake Research Promotion (HERP) was then established, and it was directly attached to the Prime Minister's office with the aim of promoting earthquake research, clarifying responsibilities and providing the public and disaster prevention organizations with research findings.

Once per month, HERP organizes meetings in order to evaluate seismic activity and publish relevant monthly reports on its official webpage. Supported by the Earthquake Research Committee of Japan (ERCJ) and the National Research Institute of Earth Science and Disaster Prevention (NIED), HERP publishes probabilistic seismic hazard maps (PSH maps). These maps illustrate the probabilities of occurrence and expected earthquake magnitudes evaluated on the basis of long-term occurrence probabilities for active faults on land and subduction zone earthquakes with a large social and economic impact (Figure 5a,b). Scenario earthquake shaking maps are also produced, illustrating ground motion intensity for specified source faults [46]. Both types of maps constitute the "National Seismic Hazard Maps for Japan" and are available to the general public and researchers on HERP's official webpage as well as the official page of the Japan Seismic Hazard Information Station (J-SHIS web portal).

The "National Seismic Hazard Maps for Japan" offer a fundamental contribution to the disaster management system, e.g., urban planning, building codes and even definition of countermeasures against large earthquakes in advance. The estimations illustrated in these maps influence the emergency seismic information, despite not being part of it. The input parameters of database scenarios and simulations used in warnings are strongly dependent on the estimations on these maps (see Section 4.2). It is well documented in the literature that PSH maps carry both types of uncertainty (Section 2.2): aleatoric uncertainty arising from variability in the source processes on a fault that changes from one earthquake to the next [47] and epistemic uncertainty associated with the evaluation of maximum magnitude and long-term occurrence rates [22].

As of January 13, 2021

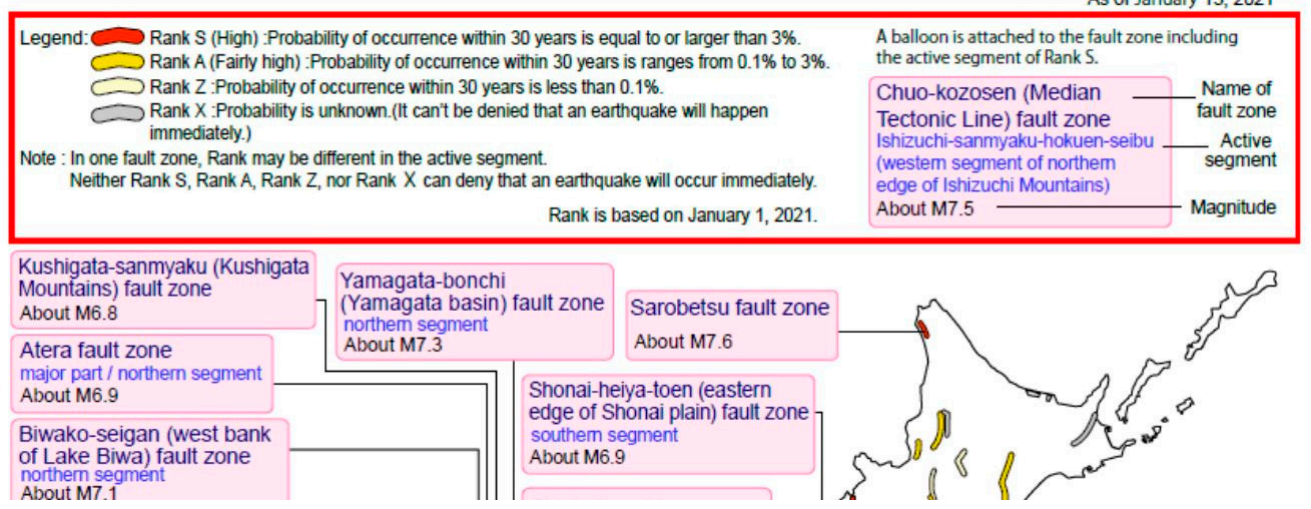

(a)

Figure 5. Cont. 


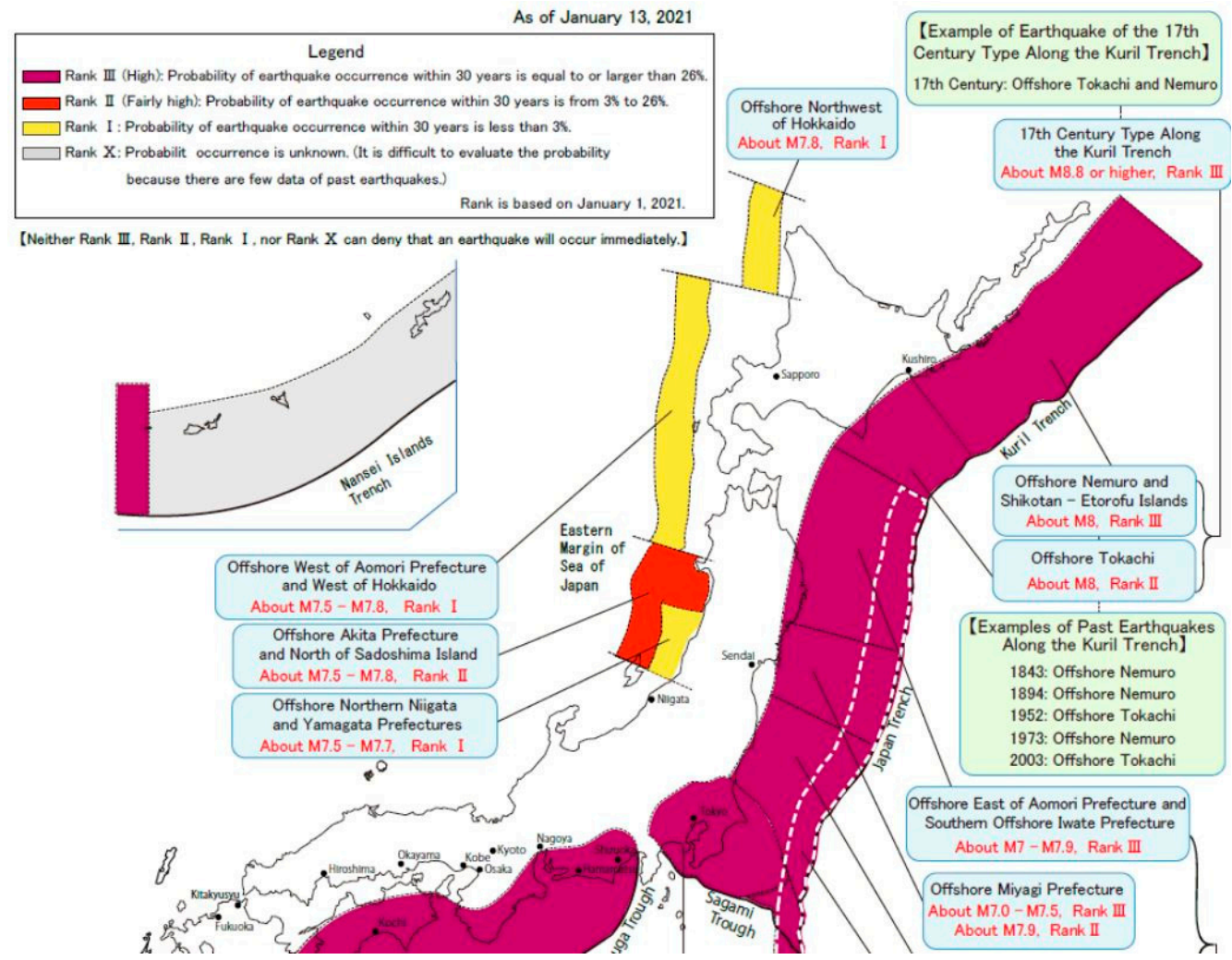

(b)

Figure 5. Part of the evaluation map of (a) major active faults (b) subduction zone earthquakes in Japan as of January 2021. Source: official HERP webpage.

The Japan Meteorological Agency (JMA), belonging to the Ministry of Land, Infrastructure, Transport and Tourism, is responsible for issuing earthquake information following an earthquake event and releasing early warnings (including tsunami warnings). JMA monitors a dense network of seismic intensity meters, seismometers, GPS stations, tide gauges and ocean bottom sensors around the clock. The earthquake information announcement involves the epicenter location, magnitude, seismic intensity parameters and possibility of tsunami occurrence. JMA issues a seismic intensity information report within two minutes, indicating the regions with a seismic intensity of three or greater; this is sent to the disaster management authorities via dedicated lines and reaches the public through local governments and the media in order to initiate emergency actions. This type of information is followed by the rapid information of basic focal parameters (hypocenter and magnitude).

In addition, JMA is responsible for issuing tsunami warnings/advisories and estimating tsunami height based on a developed tsunami forecasting system and a somewhat extensive tsunami propagation simulation database to support risk-sensitive urban planning and to provide a list of shelters and evacuation routes. JMA issues tsunami warning/advisory messages for the coastal regions of Japan within 2-3 min after the earthquake origin time. These messages provide information regarding the expected arrival times and heights of the waves based on computer simulations of tsunami waves. There are three category messages on the basis of the estimated tsunami heights (Figure 6). Since 2013, JMA has reduced the classes of tsunami heights from eight to five in consideration of uncertainty, estimation errors and impacts on disaster management [48] (Figures 6 and 7). The Tohoku Great East Japan earthquake on 11 March 2011 (Mw 9.0), the highest ever recorded in Japan, revealed the major problem of immediate determination of the exact magnitude of strong earthquakes ( 8.0 or over). Especially for these extreme cases (of large uncertainty), the content and expressions of the tsunami warning bulletins were revised: the "huge" and "high" qualitative expressions for the estimated maximum tsunami heights substituted 
for the quantitative numerical expressions that were in place until then. Moreover, the initial tsunami warning is now based on the largest seismic fault expected in the area of the earthquake or on the predefined maximum magnitude to avoid underestimation. Updates of tsunami warnings are available within 15 min after the earthquake and are based on precise analysis of Mw calculations and tsunami observations.

\begin{tabular}{|c|c|c|c|c|}
\hline \multirow{2}{*}{ Category } & \multirow{2}{*}{ Indication } & \multicolumn{2}{|c|}{$\begin{array}{c}\text { Estimated maximum tsunami } \\
\text { heights }\end{array}$} & \multirow{2}{*}{ Expected damage and action to be taken } \\
\hline & & $\begin{array}{l}\text { Quantitative } \\
\text { expression }\end{array}$ & $\begin{array}{l}\text { Qualitative } \\
\text { expression }\end{array}$ & \\
\hline $\begin{array}{l}\text { Major Tsunami } \\
\text { Warning }\end{array}$ & $\begin{array}{l}\text { Tsunami height is expected to be greater } \\
\text { than } 3 \text { meters. }\end{array}$ & $\begin{array}{l}\text { over } 10 \mathrm{~m} \\
10 \mathrm{~m} \\
5 \mathrm{~m}\end{array}$ & Huge & $\begin{array}{l}\text { Wooden structures are expected to be completely destroyed and/or washed away; anybody exposed will be } \\
\text { caught in tsunami currents. } \\
\text { Evacuate from coastal or river areas immediately to safer places such as high ground or a tsunami } \\
\text { evacuation building. }\end{array}$ \\
\hline Tsunami Warning & $\begin{array}{l}\text { Tsunami height is expected to be up to } 3 \\
\text { meters. }\end{array}$ & $3 \mathrm{~m}$ & High & $\begin{array}{l}\text { Tsunami waves will hit, causing damage to low-lying areas. Buildings will be flooded and anybody exposed will } \\
\text { be caught in tsunami currents. } \\
\text { Evacuate from coastal or river areas immediately to safer places such as high ground or a tsunami } \\
\text { evacuation building. }\end{array}$ \\
\hline Tsunami Advisory & $\begin{array}{l}\text { Tsunami height is expected to be up to } 1 \\
\text { meter. }\end{array}$ & $1 \mathrm{~m}$ & $\mathrm{~N} / \mathrm{A}$ & $\begin{array}{l}\text { Anybody exposed will be caught in strong tsunami currents in the sea. Fish farming facilities will be washed } \\
\text { away and small vessels may capsize. } \\
\text { Get out of the water and leave coastal areas immediately. }\end{array}$ \\
\hline
\end{tabular}

Figure 6. Categories of tsunami warning messages issued by JMA for coastal regions of Japan after the occurrence of strong tsunamigenic earthquakes. ${ }^{* *}$ Major Tsunami Warnings are issued in the classification of Emergency Warnings. Source: official JMA webpage.

\begin{tabular}{||c|c|l|}
\hline \multicolumn{1}{|c|}{ Warnings/advisories in effect } & Observed heights & \multicolumn{1}{|c|}{ Information bulletin expressions } \\
\hline Major Tsunami Warning & Height $>1 \mathrm{~m}$ & Actual values \\
\cline { 2 - 3 } & Height $\leqq 1 \mathrm{~m}$ & "Currently Observing" announcements \\
\hline Tsunami Warning & Height $\geqq 0.2 \mathrm{~m}$ & Actual values \\
\cline { 2 - 3 } & Height $<0.2 \mathrm{~m}$ & "Currently Observing" announcements \\
\hline Tsunami Advisory & (all cases) & Actual values \\
("Slight" for very small waves)
\end{tabular}

Figure 7. Expressions used for observed maximum heights in coastal area. Source: official JMA webpage.

In the event of large earthquakes, JMA releases earthquake early warnings a few seconds before the strong tremors arrive (secondary waves), providing people with the opportunity to take protective actions and for important key transport means (trains and elevators) to slow down [49]. These warnings, despite containing uncertainty regarding the anticipated seismic intensity, are extremely valuable for the population and infrastructure networks. JMA relays these earthquake warnings through television and radio networks and cell broadcast networks. These multiple channels ensure reception of these early warnings by the entire population [50].

Special attention is given to the prediction of large-scale earthquakes with a magnitude of around 8 and a return period of every 100-150 years, referred to as "Tokai earthquakes", via the utilization of a seismic and crustal deformation observation network throughout the region (Figure 9). JMA is responsible for evaluating the possibility of a Tokai earthquake with the support of the Earthquake Assessment Committee (EAC). The warning declaration (earthquake prediction information) is released to the public by the Prime Minister. The Tokai Earthquake Warning is considered to have a double meaning: "alert", for a strong earthquake with a magnitude of 8 or higher, and "order", to be prepared and take necessary precautions.

As in the case of Greece, Japan has a knowledge intensive organization in place to release scientific emergency information, including both objective data regarding realized phenomena and probabilistic information regarding successive phenomena to follow.

As in Greece, this organization is also the initial/original producer of information in Japan and bears the responsibility to transfer it to central and local government management authorities, to the emergency mechanism and to the media. The difference between the two countries is that Japan's organization covers multiple hazards and is more closely connected to the emergency mechanism, since the deputy director general of JMA is a member of the emergency team. This tight and centralized structure facilitates easier communication of scientists with different forms of expertise in multi-hazard situations, as well as better collaboration between scientists, emergency managers and practitioners. Additionally, Japan's organization has more power, political acceptance and prestige due to its wide scope of knowledge and strong interconnection with the highest level of political decision making. Apart from the long-term operation of earthquake and tsunami early 
warning systems in Japan, JMA's superiority in operating prediction of the next Tokai earthquake is unquestionable. However, predicting an earthquake is extremely difficult and after the Great East Japan earthquake, JMA acknowledged the possibility of magnitude underestimation of large earthquakes leading to erroneous estimations and warnings. This uncertainty has now been incorporated into the new warning message scale.

3.2.2. Public Administration Agencies as Emergency Information Sources and Management Authorities

The Central Disaster Management Council (CDMC), chaired by the Prime Minister and comprising all Cabinet members, heads of major public corporations and experts, is responsible for preparing and implementing the basic disaster management plan and earthquake disaster plans at the national level. In the event of a large-scale disaster, the Cabinet Office is engaged in collecting and disseminating accurate information, reporting to the Prime Minister, establishing the emergency system (including the Government's Disaster Management Headquarters) and overall coordination of the disaster response measures in the affected region.

The local disaster management plans are implemented by the Prefectural (Governor) and the municipal Disaster Management Councils (mayors). After receiving the earthquake information and tsunami warnings from the central government, the local authorities are able to release the emergency information to the local media and citizens within 4-20 s (in five languages) based on the J-alert system. J-alert is the satellite-based national early warning system used in Japan to directly release warnings on threats and emergencies to local media and the public (For more information, see https: / / www.centreforpublicimpact.org/case-study/disaster-technology-japan, accessed on 5 April 2021). Evacuation instructions and information on road conditions are also transmitted through this system. Updates of the emergency information are continuously provided. Additionally, the disaster emergency information is transmitted through loudspeakers and sirens to the public in coastal areas (in the case of a tsunami warning), while the warning messages appear on TV screens.

\subsubsection{The Roles of Mass Media, Social Media and Social Networks as Information Sources}

As was previously mentioned (Section 3.2.1.), as soon as an earthquake is detected and JMA issues an earthquake early warning, all of Japan's TV channels broadcast the alert message on their screens followed by instructions on how to react. This warning contains the estimated seismic intensities and expected arrival time of principal motion.

The use of social media during seismic crisis in Japan is extremely popular. In fact, JMA publishes a special report in order to familiarize the citizens with helpful Apps and Websites in the event of a disaster (Available online at http:/ / www.bousai.go.jp/kokusai/ web/img/02_bousai_guidebook_Web_EN.pdf, accessed on 15 May 2021). The smartphone application offers a wide range of information on earthquake parameters, tsunami warning and safety tips, shelters and assistance in the case of disaster. Media system dependency (MSD) theory states that "in an ambiguous situation, dependency on mass media increases because mass media outlets are likely to contain important and exclusive information that is not available from other sources" [51]. The author also states that dependency on media is intensified when people need to understand and act.

Japan has a robust, inter-sectoral and cohesive structure at the national level to deal with large-scale disaster emergencies. It is worth mentioning that the highest-level decisionmaking institution, the CDMC, consists not only of politicians and public administration officials but also scientists and experts, harmonizing political decisions with scientific information. Because of its composition and the trust that it enjoys, the CDMC does not leave much room for conflict or antagonism to be publicly presented.

The analysis of the crisis communication systems in Japan and Greece is summarized in Table 1 on the basis of the type of messages and message content. 
Table 1. Important similarities and differences in crisis communication systems in Japan and Greece categorized by the type of messages and message content (in chronological order). Source: authors' elaboration.

\begin{tabular}{|c|c|c|c|}
\hline Time of Issue & Types of Messages & Messag & Content \\
\hline $\begin{array}{l}\text { Prepared and published during the } \\
\text { quiescence period }\end{array}$ & $\begin{array}{c}\text { Long-term Evaluation of the Seismic } \\
\text { Activity } \\
\text { Informative messages } \\
\text { Aleatory variability (source processes) and } \\
\text { epistemic uncertainty (maximum } \\
\text { magnitude and occurrences rates } \\
\text { estimations). }\end{array}$ & $\begin{array}{l}\text { - National Seismic Hazard Maps } \\
\quad \text { for Japan: } \\
\text { Probabilistic Seismic Hazard Maps } \\
\text { (PSH maps) and Scenario Earthquake } \\
\text { Shaking Maps (SESM) published } \\
\text { every year. }\end{array}$ & $\begin{array}{l}\text { European Probabilistic Seismic } \\
\text { Hazard Map: At a research } \\
\text { stage } \\
\text { Seismic Hazard Zones (hazard } \\
\text { is expressed in terms of Peak } \\
\text { Ground Acceleration-PGA) and } \\
\text { is produced for usage in the } \\
\text { Greek Seismic Building Codes. }\end{array}$ \\
\hline A few days before the possible event. & $\begin{array}{c}\text { Short-term earthquake forecast } \\
\text { Warning messages } \\
\text { Probabilistic uncertainty with respect to } \\
\text { the complex phenomenon but also related } \\
\text { to the unpredictable behavioral reaction of } \\
\text { the population and to inferences by the } \\
\text { scientists. }\end{array}$ & - $\quad$ Tokai earthquake prediction & At a research stage \\
\hline
\end{tabular}

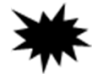

Earthquake Origin Time

Within a few minutes after the Earthquake Origin Time

\section{Rapid seismic-intensity information Informative message}

Uncertainty related to the preliminary estimations of the parameters (depending on the magnitude estimation methodology and hypocenter location determination)
- Earthquake Early Warning: epicenter and areas with expected seismic intensity $\geq 4$. Time: within seconds in the case of large earthquakes.

- Earthquake and Seismic Information: hypocenter, magnitude and seismic intensity. Time: automatic in 2-3 min, revised within 5-6 min.

- ShakeMaps: estimated seismic intensity distribution, when seismic intensity $\geq 5$, Time: several min.-hours after the earthquake,

- Mw calculation

Time: several min.-hours after the earthquake.

- $\quad$ Tsunami Warning: informing about the possibility of tsunami

Tsunami Information Informative and Warning message Epistemic uncertainty depending on first magnitude estimations and pre-simulated tsunami scenarios also related to technology or administrative issues. Uncertainty weakens when observed data

\section{generation}

Time: Within 2-3 min, updated based on observations.

- 3 levels of threat with expected wave heights. Qualitative approach: "huge" and "high" in the case of earthquake magnitude $\geq 8$ )

$$
\text { are available. }
$$

- Earthquake Early Warning: at a research stage.

- Earthquake Information: magnitude, epicenter and depth. Time: automatic in $2 \mathrm{~min}$., revised within 10-15 min.

- ShakeMaps: estimated seismic intensity distribution. Time: automatic in several min. after the earthquake, revised within min.-hours,

- Mw calculation

Time: several min.-hours after the earthquake.
Safety measures

Consulting messages

Uncertainty depending on level of preparedness
Shortly after the earthquake (within
the first hour) and continuously updated
Damage Assessment

Informative messages

Epistemic uncertainty (lack of knowledge

on the impact, reducible in time as in situ visits are realized)
Initial Tsunami Warning Message Informing about the possibility of tsunami generation.

Time: within 8-15 min, updated based on observations.

- $\quad 3$ levels of threat with numerical expressions of expected wave heights and effects on coasts.
Injuries, buildings damaged, rescue operations if necessary.

Evacuation instructions (e.g., go to open areas or move to higher places)
A few hours after the earthquake and continuously updated

Same day or a day after the earthquake and continuously updated.
Guidelines

Guiding messages

Uncertainty depending on level of preparedness

\section{Assessment of Seismic Hazard and}

Evaluation of Seismic Risk Warning messages

Uncertainty related to probabilistic

estimations and also due to inferences by the scientists. 
Table 1. Cont.

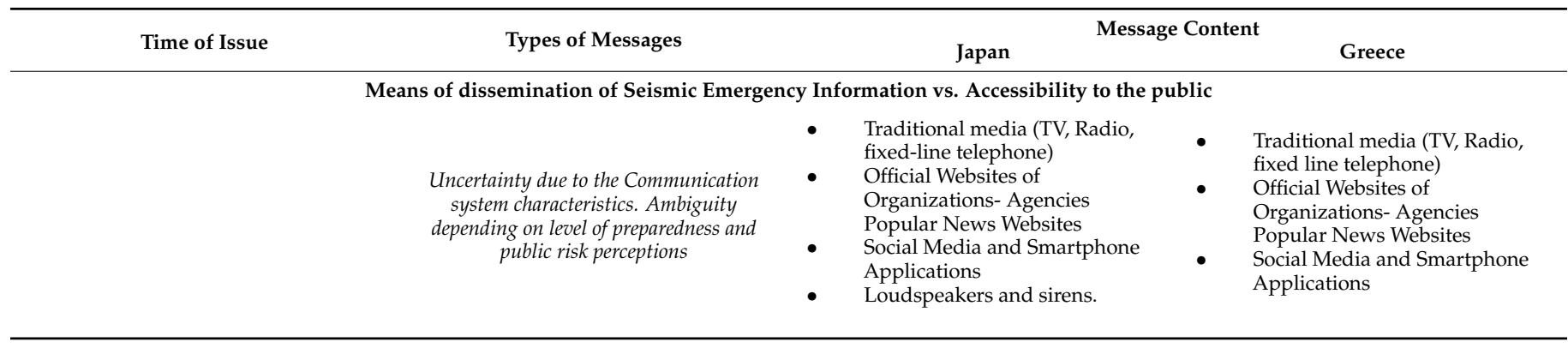

4. Examples of Actual Experiences of Seismic Crisis Communication and Impacts in Greece and Japan

\subsection{Case studies in Greece}

It is of great interest to analyze the tsunami early warning practices in Greece by examining recent actual experiences of tsunami crisis communication and management. All of the events mentioned in this section were associated with non-devastating tsunami waves. Nevertheless, these experiences represent important indications of the tsunami alert efficiency in Greece and the eastern Mediterranean Sea.

On 20 July 2017, Kos Island at the Greek-Turkish border in the Mediterranean Sea (Figure 8) experienced a strong earthquake of Mw 6.6 [52] that caused 2 casualties and hundreds of injuries due to building collapses [53]. A small-scale tsunami wave of up to $1.5 \mathrm{~m}$ arose $13 \mathrm{~min}$ after the earthquake at the island's port; this reached a height of $1.9 \mathrm{~m}$ when it arrived at Bodrum's peninsula in Turkey. The event was of limited magnitude, yet it raised intense concern regarding preparedness at the local, regional and national levels, as it revealed a lack of efficiency of tsunami warning practices in Greece. The initial earthquake information, as well as the tsunami warning (WATCH level) for the Mediterranean region, was released on time, and disaster prevention authorities were mobilized promptly. The tsunami alert was sent to GSCP (by fax) but unfortunately not received (or at least elaborated in time) by the local civil protection services (police, fire service, coastguard etc.). Consequently, the warning message never reached the local people on the island.

Emergency communication in Kos regarding the seismic event positively influenced people's behavior (remaining in open areas, sleeping outdoor etc.). However, this was not the case regarding the tsunami-associated risk. Before the earthquake, people considered a tsunami wave to be a "very large sea wave" [54], thus failing to realize that the port was hit by a tsunami and not by a storm wave. This is obvious, since people remained close to the coast after the earthquake-related shaking. In a totally missing preparedness context and with no recent memory of devastating tsunamis, the public's knowledge of tsunamis is based on other countries' experiences depicted in the media. The high touristic period might have also caused reluctance towards acknowledging the rise of the sea water as a threatening tsunami event. Only afterwards (several hours after the event) when the authorities disseminated informative videos of the tsunami did the majority of the local people become aware of what a tsunami wave is and how it can affect coastlines. After this failure, a local earthquake and tsunami warning system was established in Kos Island and Bodrum through the "Last Mile" collaborative project by NOAGI and JRC/EC supported by DG-ECHO/EC. 


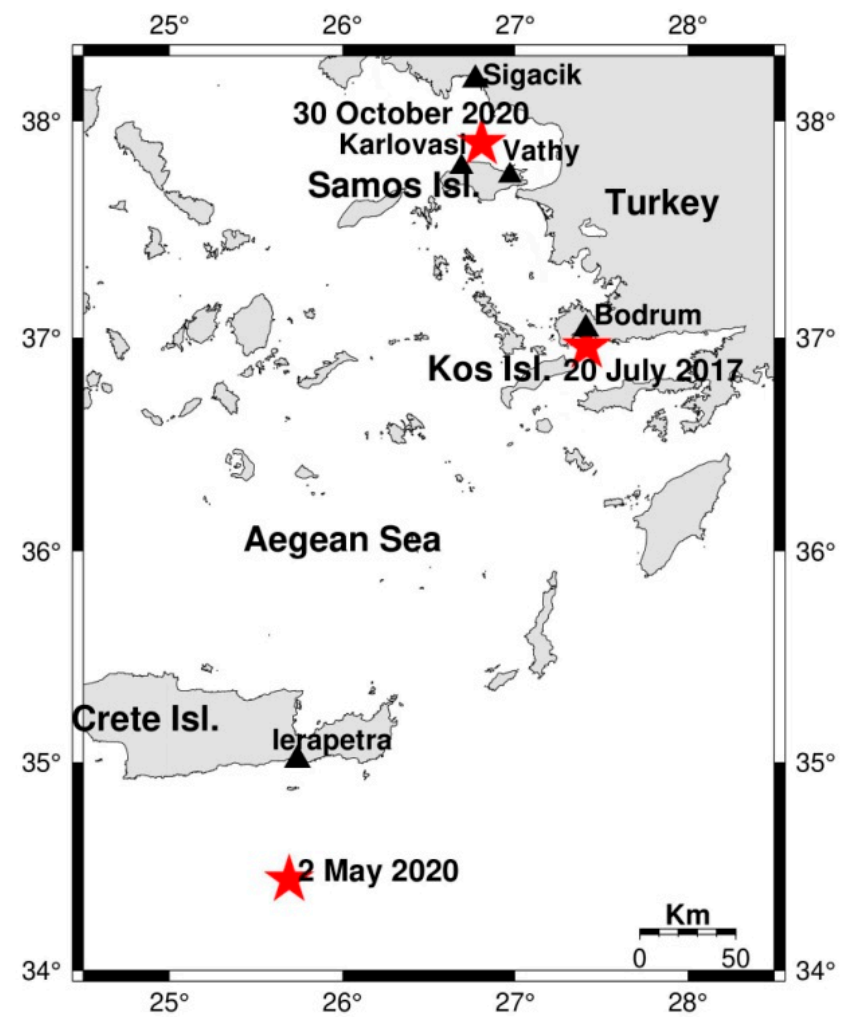

Figure 8. Map illustrating the epicenters (red stars) of the three earthquakes mentioned in Section 4.1. Source: authors' elaboration.

On 2 May 2020, a Mw 6.6 earthquake occurred in Crete (Figure 8); it was associated with a small tsunami of $16 \mathrm{~cm}$ recorded at Ierapetra tide gauge station $25 \mathrm{~min}$ after the earthquake origin time. The automatically calculated earthquake parameters led to false predictions about the tsunami wave height and effects on the coast. As soon as revisions were realized, the warning was upgraded [55], and the travel times of the tsunami wave were moved forward. Moreover, the public did not receive a tsunami alert, thus avoiding confusion by the change in the threat level alert. This change though caused confusion to the management authorities (GSCP).

Quite recently, on 30 October 2020 a strong earthquake of Mw 7.0 [56] struck the northern part of the island of Samos, Dodecanese, Greece and Izmir province in western Turkey (Figure 8). More than 115 people died due to building collapses (most of them in Izmir) and 1 person was drowned because of the tsunami in Turkey. Soon after the earthquake (15-20 $\mathrm{min})$, a tsunami was generated, causing material damage to Karlovasi town (1.7 m high reaching the coast in about $10 \mathrm{~min}$ ) and Vathy port (around $2 \mathrm{~m}$ ). In Turkey, Sigacik bay was mostly affected, with one person killed by the wave (1.9 $\mathrm{m}$ height). Preliminary earthquake information was released immediately to GSCP (3-4 min), and within $10 \mathrm{~min}$, the HL-NTWC had issued a tsunami warning message to government agencies. Due to the lack of tide gauges close to the earthquake's epicenter, water inundations along the coasts of Samos and Sigacik were reported by eyewitness observations and were released to the media before any recording of sea level change. The first recorded observations came from tide gauges more than $110 \mathrm{~km}$ from the epicenter. Nevertheless, GSCP was able to warn the public about a possible tsunami threat at the coastal zones in time before the second tsunami wave approached the coast [57]. This warning was disseminated through the European Emergency Number Service (112) (text message by SMS service) in both the Greek and English languages and was received on time. The response capacity of the National Civil Protection authorities in Greece has been improved, but shortening the alerting time still remains a challenge, considering the extremely short arrival times of the tsunami waves. Nevertheless, tsunami awareness of the local emergency officers 
(police and port departments) appeared to have improved since orders for port evacuation and relocation to higher ground were in place almost a few minutes after the earthquake, leading to zero casualties in Greece.

To summarize, the lack of (accurate) information characterizing the near real time of earthquake-tsunami crises and the strong dependence of the initial alert levels on the preliminary uncertain seismic information pose significant difficulties in crisis management. The fundamental role of an enhanced sea-level observation network is also highlighted in terms of accurate and on-time measurements. However, a prompt warning (even if it is absolutely accurate) that fails to reach the population at risk contributes little to crisis management. On top of these layers of uncertainty, a low tsunami risk perception of people in Greece represents an additional layer.

\subsection{Case Study in Japan}

On 11 March 2011, a devastating earthquake with a magnitude of Mw 9.0, known as the Great East Japan Earthquake, occurred in Tohoku, Japan, Pacific Coast (Figure 9). It is the largest earthquake ever recorded in Japan, and it is among the five largest recorded worldwide.

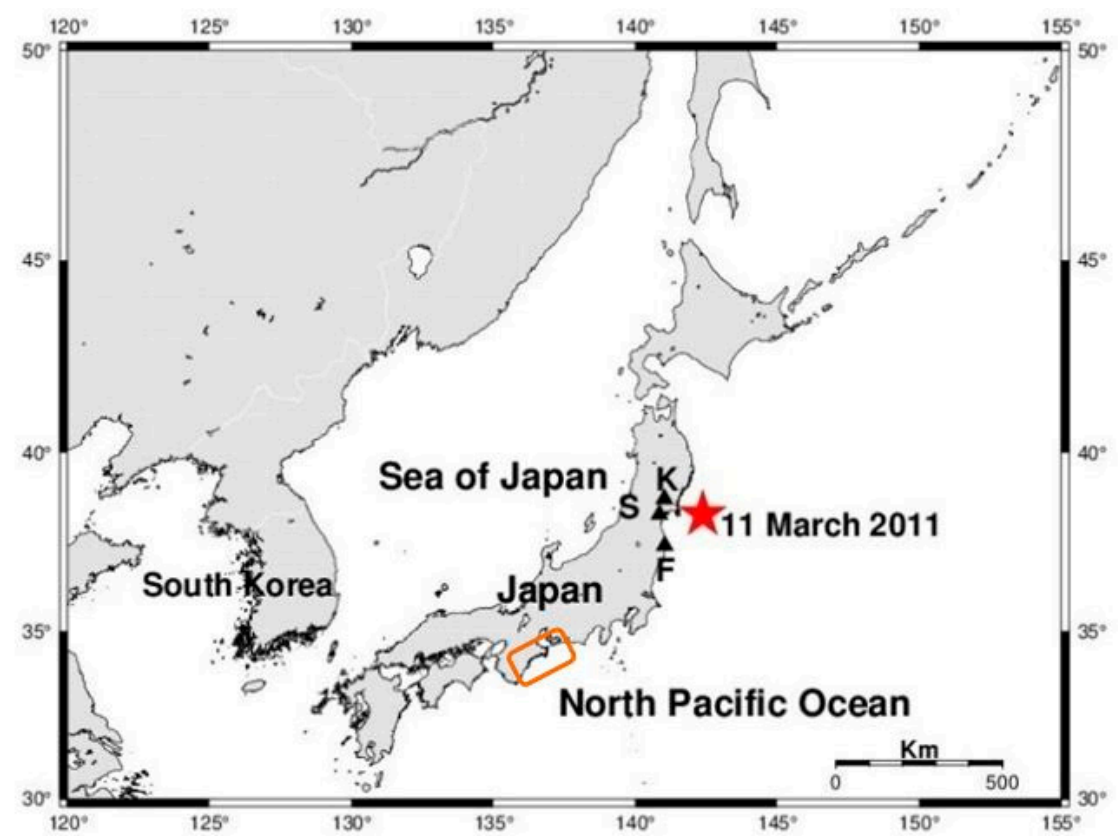

Figure 9. Map illustrating the epicenter (red star) of the Great East Japan Earthquake, 11 March 2011. $\mathrm{K}=$ Kurihara city, $\mathrm{S}=$ Sendai and $\mathrm{F}=$ Fukushima. Source: authors' elaboration. The orange rectangle illustrates the hypocentral region of Tokai earthquakes.

Japan is a tsunami-resilient community featured by high preparedness levels reflected in the advanced forecasting and communication technology, well considered urban planning, structural and non-structural countermeasures against tsunamis and an engaged population well trained for tsunami disasters. However, the country mourned over 18,000 victims after the Great East Japan Earthquake and over 4000 missing individuals [58]. The tsunami run-up height reached up to $40 \mathrm{~m}$ in Iwate prefecture [59] and a tsunami $14 \mathrm{~m}$ high caused an explosion at Fukushima nuclear power plant I [60], resulting in extensive radioactive contamination. In Sendai region, the tsunami penetrated land along a zone with a width of about $5 \mathrm{~km}$. Japan was criticized for making "methodological mistakes" [61] referring to hazard analysis and poor safety measures against tsunamis in the nuclear power plant zone. The authors of [59] argue that such a huge tsunami should not be considered a surprise, as past earthquakes of a smaller magnitude produced similar waves, revealing the impact of local topography. 
The initial magnitude estimation was 7.9 MJMA, and three minutes after the earthquake, JMA, based on this underestimated value, issued an initial tsunami warning with an underestimated forecast of tsunami heights: $6 \mathrm{~m}$ in Miyagi prefecture and $3 \mathrm{~m}$ in the coastal areas in the prefectures of Iwate and Fukushima located less than $100 \mathrm{~km}$ from the earthquake's epicenter [48]. It is worth mentioning that JMA considered the initially calculated value of the magnitude (7.9 MJMA) as being reliable, since an earthquake of this order was expected in the region. Many people did not try to evacuate since they felt safe behind a $10 \mathrm{~m}$ seawall [60], losing precious time with fateful consequences. As soon as the tsunami wave was observed at offshore tsunami buoys ( $28 \mathrm{~min}$ after the earthquake) and the source parameters were updated, JMA revised the estimation and updated tsunami warnings: over $10 \mathrm{~m}$ for Miyagi Prefecture and up to $6 \mathrm{~m}$ for the prefectures of Iwate and Fukushima.

Another important issue was electricity failure in several communities where the radio and/or public speaker system did not work due to blackouts. Consequently, the earthquake announcement and advice to move to higher places were not communicated. This failure led to later enhancing the observation facilities by installing an emergency power supply and developing a satellite-based emergency communication system as a backup in case of damage to the terrestrial facilities.

The need for information in the case of the 11 March 2011 seismic and tsunami crisis was also reflected in the use of social media. There is a great number of relevant publications [62,63], particularly in relation to Twitter [64-67], referring to the usage and contribution of social media to disaster mitigation. The earthquake caused ambiguity in the social environment. Research by [68] showed that Facebook, Mixi and Twitter were mostly used for users to gain information about the event (confirming MSD theory) and safety of friends. Smart phones became the main communication device.

The case of Greece suggests that the most critical types of uncertainty originate from low levels of awareness of the public and diverse knowledge frames of emergency managers. In the case of Japan, failures derive from the accurate and specialized content of warnings based on uncertain information, thus distorting public risk perceptions and the protective measures undertaken or not undertaken.

\section{Discussion}

The authors of this paper have attempted to present the existing standards and norms of formal and informal emergency information dissemination processes in post-earthquake crises with special emphasis put on the uncertainty issue. The fundamental objective has been to trace the impact of uncertainty on crisis management and suggest tips for crisis communication strategies in earthquake-prone countries. It was observed that uncertainty in seismic crisis communication is associated with the following: (a) lack of knowledge and data, especially within the first few minutes following the event; (b) inherent variability present in the seismic phenomenon; (c) ambiguity originating from contradictions between expert knowledge frames and different public perceptions; (d) technological gaps and failures; and (e) coordination and governance barriers.

In chronological order, the messages released to the public in seismic emergency periods are informative (reporting earthquake magnitude and epicenter, injuries, damages etc.), warning (notifying of secondary effects and tsunamis or forecasting of aftershocks), consulting and guiding (including recommendations and instructions on safety measures and protective actions). Each subsequent message group builds on the previous one and several uncertainty layers are added gradually from the informative messages through to the instructive. In the most advanced crisis communication systems (Japan), the informative and warning messages of the first minutes are based even on pre-earthquake research data and parameters, in particular the Hazard Maps and the Scenario Earthquake Shaking Maps (updated on a yearly basis).

In the course of time of the emergency period prognostic information is substituted gradually by observations and real-time data; as a result, uncertainty gives ground to 
certainty and consulting and instructive messages are updated and enhanced. While the high uncertainty messages of the first minutes are far from accurate and reliable, they are still very useful under conditions of emergency when rapid responsive actions are indispensable. This has been demonstrated by the Japanese system, which takes advantage of even the few seconds before the strong tremors arrive to release warnings in order to activate protective responses of people and the operators of infrastructure networks.

Uncertainty is also associated with the sources of emergency messages: Scientific institutions and central government management authorities in close cooperation with each other are liable basically to epistemic uncertainty; regional and local management authorities are subject to additional uncertainties arising from coordination and governance failures as well as technological deficiencies; mass and social media as well as independent expert announcements carry uncertainty that is created by diverse risk perceptions and conceptions, power relations and antagonisms.

The content of the emergency messages may either disregard or take uncertainty into account. A good example of the first case is the TWMs in Japan before 11 March 2011 (the date of the Tohoku Great East Japan earthquake) expressed then in accurate numerical values and resulting in the dramatic consequences of the disaster of 2011. A good example of the second case is the Japan's revised classification of TWMs after the 2011 disaster where the quantitative terms were substituted by qualitative to prevent creation of false perceptions. However the information that is overly generalized and vague does not raise awareness.

\section{Conclusions and Recommendations}

The important research query that the authors have raised from the beginning of the present work refers to the impact of uncertainty on crisis dynamics and disaster management. The major relevant findings are presented below:

i. Epistemic uncertainty and variability inherent to the phenomenon are present in every case of seismic-prone country and influences the management actions and the level of trust toward the sources of information. It is evident that the emergency information of the first minutes after the initial seismic shock should be produced and disseminated as "transitional" information, thereby allowing it to be updated and for further details to be provided later. The communities that are affected by such crises should be trained to expect and live with the intermediary, insufficient and imprecise content of the first round of messages. Management authorities, on the other hand, should follow the precautionary principle at this early crisis stage and issue only short-term but maximum protection instructions.

ii. Ambiguity and cognitive diversity influences behavioral actions and adaptation/ protection measures. Diverging cognitive frameworks create mistrust, cognitive disorder and chaos in the affected community. In general terms, cooperation/unification of the several scientific agencies and viewpoints and their alignment with political decision-making represent a good strategy that does not leave much room for disagreements in periods of emergency. In the case of Greece, the connections of the scientific agencies with the political/administrative hierarchy have remained weak, and the political and scientific antagonisms not only hamper crisis management but may cause the generation of secondary crises. In contrast to the case of Greece, Japan is featured by strong connections between the scientific institutes and the political/administrative structure at the highest level of the political hierarchy (the Cabinet's Office), enhancing the trustworthiness of both scientific guidance and political decision-making. However, this tight and rigid structure at the national level may create difficulties in coordination with and embeddedness of the local level into the emergency information exchange and decision-making system.

iii. Uncertainty due to governance and coordination problems has important detrimental effects on prompt warning and response time. Japan represents a coherent administrative structure with well-trained members to address effectively large-scale disaster 
emergencies. On the other hand, in Greece, low coordination capacity was observed in the case of the Kos seismic crisis: the processing of emergency messages from the centrally located HL-NTWC to the distant island of Kos was delayed. In a totally missing preparedness context, the tsunami risk perceptions of the local people were shaped exclusively by past media reports referring to only huge tsunamis with devastating results. Therefore, the local community did not even have the opportunity to recognize the potentially dangerous local phenomenon.

iv. Technological gaps are present in all seismic-prone countries and influence information circulation and accessibility. Power outages and heavy traffic in official webpages are common problems during a seismic crisis. When the transmission of the emergency messages is interrupted, disaster preparedness and awareness are essential to save lives.

Both experiences in Greece and Japan clearly indicate the merits but also the weaknesses of the highly centralized emergency communication systems. On the one hand, they are beneficial in terms of wide public acceptance, confidence and legitimacy, but, on the other hand, they are disadvantageous in that they allow only limited feedback from the local level empirical data, biophysical risks [69] and local risk perceptions and cultures.

After the aforementioned discussion and conclusions, the following recommendations seem to be critical for seismic crisis communication strategies to reduce uncertainty:

- $\quad$ Promote research in seismology to reduce epistemic uncertainty;

- $\quad$ Provide for alternative means of communication (resilience) to reduce uncertainty from technological failures;

- $\quad$ Upgrade preparedness level and organize training courses for the population, first responders and managers on the standardized emergency communication procedures to avoid misconceptions of messages and false perceptions during the crisis;

- Ensure a commonly shared minimum risk knowledge level among emergency managers;

- Immediately after the earthquake origin, issue only short-term but maximum protection consulting and instructive messages (apply the precautionary principle);

- Take care to constantly update the first, highly uncertain emergency messages and give advice to the population to constantly search for refreshed information;

- $\quad$ Connect recent pre-disaster research findings (hazard and shake maps) with the informative and warning messages of the first minutes after the earthquake origin;

- Do not cover up uncertainty in the emergency messages;

- Do not issue warning messages that are very specific/accurate (hiding uncertainty) or very general (i.e., ineffective in triggering protective responses);

- Build a unique, unified and unanimous scientific-crisis management structure at central/national level but ensure constant exchange of information and feedback from and to the regional and local level as well as independent experts. Multihazard and multi-risk observatories at the regional/local level could contribute to this direction by performing the following functions: (a) receive centrally processed scientific information and data and respond with feedback information on the basis of local observations; (b) make local observations of primary and secondary hazards and systemic risk dynamics with the support of new technologies; and (c) operate two-way emergency information communication with the exposed regional/local communities.

It should be expected that this combination of top-down and bottom-up styles of emergency communication will reduce uncertainty.

Author Contributions: Conceptualization, A.F. and K.S.; methodology, K.S.; writing-original draft preparation, A.F.; writing-review and editing, A.F. and K.S.; supervision, K.S. Both authors have read and agreed to the published version of the manuscript.

Funding: This research received no external funding. 
Institutional Review Board Statement: Not applicable.

Informed Consent Statement: Not applicable.

Data Availability Statement: Not applicable.

Conflicts of Interest: The authors declare no conflict of interest.

\begin{tabular}{|c|c|}
\hline CDMC & Central Disaster Management Council \\
\hline J-SHIS & Japan Seismic Hazard Information System \\
\hline EAC & Earthquake Assessment Committee \\
\hline MSD Theory & Media System Dependency Theory \\
\hline EMSC & European Mediterranean Seismological Centre \\
\hline NEAC & National Emergency Aid Centre \\
\hline EPPO & Earthquake Planning and Protection Organization \\
\hline NHOC & National Health Operations Center \\
\hline ERCC & Emergency Response Coordination Centre of the European Union \\
\hline NIED & National Research Institute of Erath Science an Disaster Prevention \\
\hline ERCJ & Earthquake Research Committee in Japan \\
\hline NOAGI & Institute of Geodynamics, National Observatory of Athens \\
\hline ETAS model & Epidemic-Type Aftershock Sequence \\
\hline GPS & Global Positioning System \\
\hline OBS & Ocean Bottom Sensors \\
\hline GSCP & General Secretariat for Civil Protection \\
\hline PSH maps & Probabilistic Seismic Hazard maps \\
\hline GTS & Global Tele-communication System \\
\hline PSHA & Probabilistic Seismic Hazard Assessment \\
\hline HCG & Hellenic Coast Guard \\
\hline PSSC & $\begin{array}{l}\text { Permanent Special Scientific Committee for the Assessment of Seismic Hazard } \\
\text { and the Evaluation of Seismic Risk }\end{array}$ \\
\hline HERP & Headquarters for Earthquake Research Promotion \\
\hline HFS & Hellenic Fire Service \\
\hline HL-NTWC & Hellenic National Tsunami Warning Center \\
\hline PTHA & Probabilistic Tsunami Hazard Assessment \\
\hline HNDS & Hellenic National Defence General Staff \\
\hline PTWC & Pacific Tsunami Warning Center \\
\hline $\mathrm{HPF}$ & Hellenic Police Force \\
\hline SHA & Seismic Hazard Assessment \\
\hline HUSN & Hellenic United Seismic Network \\
\hline TEW & Tsunami Early Warning \\
\hline IOC-UNESCO & Intergovernmental Oceanographic Commission of UNESCO \\
\hline TWM & Tsunami Warning Messages \\
\hline ITSAK & Institute of Engineering Seismology and Earthquake Engineering \\
\hline JMA & Japan Meteorological Agency \\
\hline JRC & Joint Research Centre \\
\hline
\end{tabular}

\section{References}

1. Perseus, A. Greek-English Lexicon, Digital Library. Available online: https://www.perseus.tufts.edu/hopper/ (accessed on 10 October 2020).

2. Seeger, M.W.; Sellnow, T.L.; Ulmer, R.R. Communication, Organization and Crisis. Commun. Yearb. 1999, 21, 231-275. [CrossRef]

3. Fediuk, T.A.; Coombs, W.T.; Botero, I.C. Exploring crisis from a receiver perspective: Undertaking stakeholder reactions during crisis events. In The Handbook of Crisis Communication; Coombs, W.T., Holladay, S.J., Eds.; Wiley: Maiden, MA, USA, 2012; pp. 635-656.

4. James, E.M.; Wooten, L.P.; Dushek, K. Crisis management: Informing a new leadership research agenda. Acad. Manag. Ann. 2011, 5, 455-493. [CrossRef]

5. Kahn, W.A.; Barton, M.A.; Fellows, S. Organizational Crises and the Disturbance of Relational Systems. Acad. Manag. Rev. 2013, 38, 377-396. [CrossRef] 
6. Bundy, J.; Pfarrer, M.D.; Short, C.E.; Coombs, W.T. Crisis and Crisis Management: Integration, interpretation and research development. J. Manag. 2016, 43, 1661-1692. [CrossRef]

7. Lagadec, P. La Gestion des Crises, Outils de Réflexion à l’ Usage des Décideurs; McGraw-Hill: Paris, France, 1991.

8. United States Department of Health and Human Services-Centers of Disease Control and Prevention, 2012. Crisis and Emergency Risk Communication, 2012 Edition. Available online: https:/ / stacks.cdc.gov/view/cdc/22159 (accessed on 1 November 2020).

9. Gray, G.; Ropeik, D.P. Dealing with the Dangers of Fear: The Role of Risk Communication. Health Aff. 2002, 21, 106-116. [CrossRef] [PubMed]

10. Wray, R.J.; Jupka, K. What Does the Public Want to Know in the Event of a Terrorist Attack Using Plague? Biosecur. Bioterror. 2004, 2, 8-15. [CrossRef]

11. Seeger, M.W. Best practices in crisis communication: An expert panel process. J. Appl. Commun. Res. 2006, 34, 232-244. [CrossRef]

12. Wilson, T.D. Human information behaviour. Inf. Sci. 2000, 3, 49-56.

13. Chowdhury, S.; Gibb, F.; Landoni, M. A model of uncertainty and its relation to information seeking and retrieval (IS\&R). J. Doc. 2014, 70, 575-604.

14. Kouskouna, V.; Sakkas, G.; Cecic, I.; Tsimpidaros, V.I.; Sakkas, S.; Kaviris, G.; Tertulliani, A. Earthquake induced crises: Game Tree approached risk communication and lessons learnt. Ann. Geophys. 2020. [CrossRef]

15. Sapountzaki, K. Emergency Evacuation of the Population in Case of Earthquake; Earthquake Planning and Protection Organization (EPPO): Athens, Greece, 2002; Volume 3, p. 72. Available online: https:/ / ecpfe.oasp.gr/sites/default/files/eee_0.pdf (accessed on 1 June 2021).

16. Liu, B.F.; Bartz, L.; Duke, N. Communicating Crisis uncertainty: A review of the knowledge gaps. Public Relat. Rev. 2016, 42, 479-487. [CrossRef]

17. Doyle, E.E.; Johnston, D.M.; Smith, R.; Paton, D. Communicating model uncertainty for natural hazards: A qualitative systematic thematic review. Int. J. Disaster Risk Reduct. 2019, 33, 449-476. [CrossRef]

18. Ogata, Y. Statistical models for earthquake occurrences and residual analysis for point processes. J. Am. Stat. Assoc. 1988, 83, 9-27. [CrossRef]

19. Ogata, Y. Significant improvements of the space-time ETAS model for forecasting of accurate baseline seismicity. Earth Planets Space 2011, 53, 217-229. [CrossRef]

20. Vere-Jones, D. Earthquake prediction-A statistician's view. J. Phys. Earth 1978, 26, 129-146. [CrossRef]

21. Becker, J.S.; Potter, S.H.; McBride, S.K.; Wein, A.; Doyle, E.E.; Paton, D. When the earth doesn't stop shaking: How experiences over time influenced information needs, communication, and interpretation of aftershock information during the Canterbury Earthquake Sequence, New Zealand. Int. J. Disaster Risk Reduct. 2019, 34, 397-411. [CrossRef]

22. Beven, K.J.; Almeida, S.; Aspinall, W.P.; Bates, P.D.; Blazkova, S.; Borgomeo, E.; Freer, J.; Goda, K.; Hall, J.W.; Phillips, J.C.; et al. Epistemic uncertainties and natural hazard risk assessment-Part 1: A review of different natural hazard areas. Nat. Hazards Earth Syst. Sci. 2018, 18, 2741-2768. [CrossRef]

23. Allen, T.I.; Wald, D.J.; Hotovec, A.J.; Lin, K.; Earle, P.S.; Marano, K.D. An Atlas of ShakeMaps for Selected Global Earthquakes; Open-File Report; US Geological Survey: Golden, CO, USA, 2008; p. 35.

24. Mc Guire, R.K.; Shedlock, K.M. Statistical uncertainties in seismic hazard evaluations in the United States. Bull. Seismol. Soc. Am. 1981, 71, 1287-1308.

25. Rebez, A.; Slejko, D. Introducing epistemic uncertainties into seismic hazard assessment for the broader Vittorio Veneto area (N.E. Italy). Boll. Geofis. Teeorica Appl. 2004, 45, 305-320.

26. England, P.; Howell, A.; Jackson, J.; Synolakis, C. Palaeotsunamis and tsunami hazards in the Eastern Mediterranean. Philos. Trans. R. Soc. A Math. Phys. Eng. Sci. 2015, 373, 20140374. [CrossRef]

27. Shuto, N.; Fujima, K.A. Short History of tsunami research and countermeasures in Japan. Proc. Jpn. Acad. Ser. B 2009, 85, 267-275. [CrossRef]

28. Goda, K.; Mai, P.M.; Yasuda, T.; Mori, N. Sensitivity of tsunami wave profiles and inundation simulations to earthquake slip and fault geometry for the 2011 Tohoku earthquake. Earth Planets Space 2014, 66, 105. [CrossRef]

29. Tyagunov, S.; Pittore, M.; Wieland, M.; Parolai, S.; Bindi, D.; Fleming, K.; Zschau, J. Uncertainty and sensitivity analysis in seismic risk assessments on the example of Cologne, Germany. Nat. Hazards Earth Syst. Sci. 2014, 14, 1625-1640. [CrossRef]

30. Liu, C.; Fang, D.; Zhao, L. Reflection on earthquake damage of buildings in 2015 Nepal earthquake and seismic measures for post-earthquake reconstruction. Structures 2021, 30, 647-658. [CrossRef]

31. Ma, Y.; Che, Y.; Gong, J. Behavior of corrosion damaged circular reinforced concrete columns under cyclic loading. Constr. Build. Mater. 2012, 29, 548-556. [CrossRef]

32. Reynolds, B.; Seeger, M.W. Crisis and emergency risk communication as an integrative model. J. Health Commun. 2005, 10, 43-455. [CrossRef] [PubMed]

33. Brasher, D.E. Communication and Uncertainty Management. J. Commun. 2001, 51, 477-497. [CrossRef]

34. Berger., C.R.; Calabrese, R.J. Some explorations in initial interaction and beyond: Toward a developmental theory of interpersonal communication. Hum. Commun. Res. 1975, 1, 99-112. [CrossRef]

35. Babrow, A.S.; Hines, S.C.; Kasch, C.R. Managing uncertainty in illness explanation: An application of problematic integration theory. In Explaining Illness: Research, Theory, and Strategies; Whaley, B.B., Ed.; Lawrence Erlbaum Associates Publishers: Hillsdale, NJ, USA, 2000; pp. 41-67. 
36. Bradac, J.J. Theory comparison: Uncertainty reduction, problematic integration, uncertainty management, and other curious constructs. J. Commun. 2001, 51, 456-476. [CrossRef]

37. Rains, S.A.; Tukachinsky, R. An examination of the relationship among uncertainty, appraisal, and information-seeking behavior proposed in uncertainty management theory. Health Commun. 2015, 30, 339-349. [CrossRef]

38. Babrow, A.S. Uncertainty, value, communication, and problematic integration. J. Commun. 2001, 51, 553-573. [CrossRef]

39. Rogers, M.B.; Amlôt, R.; Rubin, G.J.; Wessely, S.; Krieger, K. Mediating the social and psychological impacts of terrorist attacks: The role of risk perception and risk communication. Int. Rev. Psychiatry 2007, 19, 279-288. [CrossRef] [PubMed]

40. Comes, T.; Adrot, A.; Rizza, C. Decision-making under uncertainty. In Science for Disaster Risk Management 2020: Acting Today, Protecting Tomorrow; Casajus Valles, A., Marin Ferrer, M., Poljanšek, K., Clark, I., Eds.; EUR 30183 EN; Publications Office of the European Union: Luxembourg, 2020; Chapter 4.2; ISBN 978-92-76-18181-1. [CrossRef]

41. Meier, P. Next Generation Humanitarian Computing; ACM Press: New York, NY, USA, 2014; p. 1573.

42. Comes, T.; Van de Walle, B. Information systems for humanitarian logistics: Concepts and design principles. In Supply Chain Management for Humanitarians: Tools for Practice; Kovacs, G., Spens, K., Haavisto, I., Eds.; Kogan Page: London, UK, 2016; pp. 257-284.

43. Peppoloni, S.; Di Capua, G. The meaning of Geoethics. In Geoethics, Ethical Challenges and Case Studies in Earth Sciences; Wyss, M., Peppoloni, S., Eds.; Elsevier Inc.: Waltham, MA, USA, 2015; Chapter 1. [CrossRef]

44. Gilbert, C. Crisis Analysis: Between Normalization and Avoidance. J. Risk Res. 2007, 10, 925-940. [CrossRef]

45. Papadopoulos, G.A. Communicating to the General Public Earthquake Prediction Information: Lessons Learned in Greece. In Geoethics, Ethical Challenges and Case Studies in Earth Sciences; Wyss, M., Peppoloni, S., Eds.; Elsevier Inc.: Waltham, MA, USA, 2015; Chapter 19. [CrossRef]

46. Fujiyama, H.; Kawai, S.; Aoi, S.; Morikawa, N.; Senna, S.; Kobayashi, K.; Ishii, T.; Okumura, T.; Hayakawa, Y. National Seismic Hazard Maps of Japan. Bull. Earthq. Res. Inst. Univ. Tokyo 2006, 81, 221-232.

47. Anderson, J.G.; Brune, J.N. Probabilistic Seismic Hazard Analysis: Improving Consistency with Precarious Rock Observations by Removing the Ergodic Assumption. In Proceedings of the 12th World Conference on Earthquake Engineering, Auckland, New Zeland, 30 January-4 February 2000.

48. Japan Meteorological Agency (JMA). Lessons Learned from the Tsunami Disaster Caused by the 2011 Great East Japan Earthquake and Improvements in JMA's Tsunami Warning System. 2013. Available online: https://www.data.jma.go.jp/svd/eqev/data/en/ tsunami/LessonsLearned_Improvements_brochure.pdf (accessed on 1 April 2021).

49. Japan Meteorological Agency (JMA). New JMA Brochure. 2020. Available online: https://www.jma.go.jp/jma/en/Activities/ brochure202003.pdf (accessed on 1 April 2021).

50. Yamasaki, E. What We Can Learn from Japan's Early Earthquake Warning System. Momentum 2012, 1, 26. Available online: https:/ / repository.upenn.edu/momentum/vol1/iss1/2 (accessed on 1 April 2021).

51. Ball-Rokeach, S.J. A theory of media power and a theory of media use: Different stories, questions, and ways of thinking. Mass Commun. Soc. 1998, 1, 5-40. [CrossRef]

52. Cordrie, L.; Gailler, A.; Heinrich, P.; Briole, P.; Ganas, A. The 20 July 2017 Mw =6.6 Bodrum-Kos Earthquake, Southeast Aegean Sea: Contribution of the Tsunami Modeling to the Assessment of the Fault Parameters. Pure Appl. Geophys. 2021. [CrossRef]

53. Earthquake Planning and Protection Organization (EPPO) Report for 21 July 2017 Kos Earthquake Published on 27 July 2017. Available online: https:/ / www.oasp.gr/node/3644 (accessed on 1 April 2021).

54. Papageorgiou, A.; Tsimim, C.; Orfanogiannaki, K.; Papadopoulos, G.; Sachpazi, M.; Lavigne, F.; Grancher, D. Tsunami Questionnaire Survey in Heraklion Test Site, Crete Island, Greece. In Geophysical Research Abstracts, Proceedings of the European Geosciences Union (EGU), Vienna, Austria, 12-17 April 2015; EGU2015-10784; European Geosciences Union (EGU) General Assemblies Publications: Munich, Germany, 2015.

55. Papadopoulos, G.; Lekkas, E.; Katsetsiadou, K.N.; Rovythakis, E.; Yahav, A. Tsunami Alert Efficiency in the Eastern Mediterranean Sea: The 2 May 2020 Earthquake (Mw6.6) and Near-Field Tsunami South of Crete (Greece). GeoHazards 2020, 1, 44-60. [CrossRef]

56. Ganas, A.; Elias, P.; Briole, P.; Valkaniotis, S.; Escartin, J.; Tsironi, V.; Karasante, I.; Kosma, C. Co-seismic and post-seismic deformation, field observations and fault model of the 30 October $2020 \mathrm{Mw}=7.0$ Samos earthquake, Aegean Sea. Acta Geophys. 2021, 69, 999-1024. [CrossRef]

57. Triantafyllou, I.; Gogou, M.; Mavroulis, S.; Lekkas, E.; Papadopoulos, G.A.; Thravalos, M. The Tsunami Caused by the 30 October 2020 Samos (Aegean Sea) Mw7.0 Earthquake: Hydrodynamic Features, Source Properties and Impact Assessment from Post-Event Field Survey and Video Records? J. Mar. Sci. Eng. 2021, 9, 68. [CrossRef]

58. Kazama, M.; Noda, T. Damage statistics (Summary of the 2011 off the Pacific Coast of Tohoku Earthquake damage). Soils Found. 2012, 52, 780-792. [CrossRef]

59. Tsuji, Y.; Satake, K.; Ishibe, T.; Harada, T.; Nishiyama, A.; Kusumoto, S. Tsunami Heights along the Pacific Coast of Northern Honshu Recorded from the 2011 Tohoku and Previous Great Earthquakes. Pure Appl. Geophys. 2014, 171, 3183-3215. [CrossRef]

60. Koshimura, S.; Shuto, N. Response to the 2011 Great East Japan Earthquake and Tsunami disaster. Philos. Trans. A 2015, 373, 20140373. [CrossRef] [PubMed]

61. Synolakis, C.; Kânoğlu, U. The Fukushima accident was preventable. Philos. Trans. A 2015, 373, 20140379. [CrossRef]

62. Liu, B.F.; Fraustini, J.D.; Jin, Y. Social Media Use during Disaster: How Information Form and Source Influence Intended Behavioral Responses. Commun. Res. 2016, 43, 626-646. [CrossRef] 
63. Peary, B.D.; Rajib Shaw, R.; Takeuchi, Y. Utilization of Social Media in the East Japan Earthquake and Tsunami and its Effectiveness. J. Nat. Disaster Sci. 2012, 34, 3-18. [CrossRef]

64. Yoshitsugu, Y. Roles of Social Media at the Time of Major Disasters Observed in the Great East Japan Earthquake: Twitter as an Example. NHK Broadcasting Culture Research Institute, Japan Broadcasting Operation. 2011. Available online: https: / / www.nhk.or.jp/bunken/english/reports/summary/201107/02.html (accessed on 20 May 2021).

65. Doan, S.; Vo, B.K.; Collier, N. An Analysis of Twitter Messages in the 2011 Tohoku Earthquake. In Lecture Notes of the Institute for Computer Sciences, Social Informatics and Telecommunications Engineering; Electronic Healthcare; Kostkova, P., Szomszor, M., Fowler, D., Eds.; Springer: Berlin/Heidelberg, Germany, 2012. [CrossRef]

66. Kaigo, M. Social media usage during disasters and social capital: Twitter and the Great East Japan earthquake. Keio Commun. Rev. 2012, 34, 1-35.

67. Thomson, R.; Ito, N.; Suda, H.; Lin, F.; Liu, Y.; Hayasaka, R.; Isochi, R.; Wang, Z. Trusting Tweets: The Fukushima Disaster and Information Source Credibility on Twitter. In Proceedings of the 9th International ISCRAM Conference, Vancouver, BC, Canada, 22-25 April 2012.

68. Jung, J.Y. Social media use and goals after the Great East Japan Earthquake. First Monday 2012, 17. [CrossRef]

69. Cutter, S.L. Vulnerability to Environmental Hazards. Prog. Hum. Geogr. 1996, 20, 529-539. [CrossRef] 